\title{
Infecciones por Acinetobacter baumannii pan-resistente. Consideraciones epidemiológicas y de manejo antimicrobiano actualizado
}

\author{
ALEXIS DIOMEDI P.
}

\author{
Acinetobacter baumannii pandrug-resistant. Update in epidemiological and \\ antimicrobial managing issues
}

In the last two decades Acinetobacter baumannii has emerged as a major relevant world nosocomial pathogen. A. baumannii can be a causal agent of diseases like pneumonia, bacteremia, meningitis, soft tissue and urinary tract infections, associating to high mortality. Several national and foreign communications reveal the isolation of A. baumannii resistant to almost all commercially available antimicrobial agents, drastically limiting the therapeutic options.To optimize the therapy of these infections, the need of development of new antibacterial agents is raised as is the revival of certain forgotten compounds, as the polymyxins. In order to check and evaluate the information on the management of multi-resistant A. baumannii infections, we performed a systematical review of the medical scientific literature, that included Medline and LILACS, identifying and categorizing the clinical relevancy of the sources gathered to the date of this investigation. Clinically relevant epidemiological aspects, microbiological information and clinical studies in patients with pandrug (AB-PDR) or multidrug resistant (AB-MDR) A.baumannii infections were reviewed. The response adapted to the management of AB-PDR infection is complex, its eradication needs adherence to suitable practices of infection control and the prudent and effective use of antimicrobial therapy. Potential options of therapy could be colistin, betalactam associations with sulbactam and tetracyclines, but there are no random and controlled studies in the matter.

Key words: Acinetobacter baumannii, antimicrobial resistance, colistin, sulbactam.

Palabras claves: Acinetobacter baumannii; resistencia antimicrobiana; colistin; sulbactam.

Acinetobacter baumannii ha emergido como un significativo patógeno nosocomial en pacientes hospitalizados en todo el mundo. Las infecciones del torrente sanguíneo por A. baumannii alcanzan al $2 \%$ del total de las adquiridas en hospitales y al $6 \%$ de las neumonías asociadas a ventilador mecánico entre 1992 y 1997 en E.U.A.. En Europa, entre 1997 y 1999, A. baumannii fue el noveno patógeno más común en infecciones hospitalarias del torrente sanguíneo. En Latinoamérica alcanza al 5,3\% de todos los aislados de bacteriemias nosocomiales ${ }^{2,3}$. En Chile las especies de Acinetobacter representaron $9,4 \%$ de todos los brotes nosocomiales reportados entre 1985 y $2002^{4}$. En 1988 se comunican los primeros brotes nacionales por tal patógeno, motivando desarrollo de normas específicas para su manejo epidemiológico 5 .

Según el sistema nacional de vigilancia epidemiológica del Ministerio de Salud MINSAL (Tabla 1) A. baumannii representa la primera causa de neumonía asociada a ventilador mecánico en

Hospital Del Salvador. Unidad de Infectología.

Instituto Nacional del Tórax.

Instituto Nacional de Oncología.

Recibido: 18 mayo 2005

Aceptado: 10 julio 2005 
Tabla 1. Relevancia de Acinetobacter baumannii en la vigilancia de IIH con agente etiológico conocido. Chile 2000-2003

\begin{tabular}{|c|c|c|c|c|c|c|c|c|}
\hline \multirow[t]{3}{*}{ Tipo de IIH con agente conocido } & \multicolumn{8}{|c|}{ Año de vigilancia } \\
\hline & \multicolumn{2}{|c|}{2000} & \multicolumn{2}{|c|}{2001} & \multicolumn{2}{|c|}{2002} & \multicolumn{2}{|c|}{2003} \\
\hline & $\mathbf{n}$ & $\%$ & $\mathbf{n}$ & $\%$ & $\mathbf{n}$ & $\%$ & $\mathbf{n}$ & $\%$ \\
\hline Neumonía asociada a ventilación mecánica en adultos & 182 & 36,2 & 213 & 38,8 & 77 & 27,2 & 248 & 38,2 \\
\hline Infección del torrente sanguíneo asociada a CVC en adultos & $57 *$ & 19,1 & 29 & 17,1 & 14 & 9,7 & 20 & 8,7 \\
\hline Infección del tracto urinario asociada a catéter urinario & 63 & 6,6 & 90 & 10,6 & 64 & 7,6 & 56 & 4,4 \\
\hline
\end{tabular}

*: Años 1999-2000. CVC: catéter venoso central

Fuente: MINSAL. Informes de vigilancia epidemiológica IIH [119-122].

adultos entre 2000 y 2003 con 38,2\% del total para este último año ${ }^{6-9}$. La misma fuente comunica que en infecciones del torrente circulatorio en adultos, $A$. baumannii fue la tercera etiología con $8,7 \%$, y la séptima causa en ITU asociada a catéter urinario $(4,4 \%)$ para 2003 en Chile?

Si bien las infecciones por este bacilo gramnegativo son raras, su incidencia se acrecienta continuamente. Acinetobacter baumannii puede causar una multitud de infecciones incluyendo neumonía, bacteriemia, meningitis, infecciones del tracto urinario, peritonitis e infecciones de piel y tejidos blandos ${ }^{10}$. La mortalidad de tales infecciones es alta. La tasa de mortalidad cruda asociada a bacteriemia es de alrededor de $52 \%$ y la asociada a neumonía está entre 23 y $73 \%{ }^{11-16}$. La resistencia múltiple a antimicrobianos es muy frecuente en esta especie lo que complica su erradicación y su terapéutica en infecciones graves. Se han identificado aislados resistentes a prácticamente todos los antimicrobianos comercialmente disponibles, lo que limita extremadamente sus alternativas terapéuticas ${ }^{17-20}$.

Conceptualmente se definen como multi-resistentes aquellas cepas de A. baumannii (ABMR) que sólo preservan susceptibilidad a carbapenémicos, amikacina, sulbactam y minociclina $^{21,22}$, y como A. baumannii pan-resistentes (AB-PR) a las cepas que son además resistentes a carbapenémicos y que regularmente son sólo susceptibles a polimixinas como colistín ${ }^{23,24}$. Existen reportes recientes de AB-PR resistentes a colistin $^{25}$.

El primer brote de AB-MR comunicado en la literatura científica, que corresponde a una serie de 59 pacientes en Nueva York E.U.A., data de septiembre de $1991^{21}$. Hsueh y cols reportaron en 2002 una serie de 79 pacientes con AB-PR ${ }^{21}$. En Chile, Diomedi y cols comunicaron en 2002 el primer aislado clínico chileno de AB-PR en un paciente con neumonía nosocomial ${ }^{26}$. Posteriormente Beltrán y cols reportaron en 2004, 12 casos de AB-MR en dos centros nacionales también bajo la presentación de neumonía nosocomial $^{27}$.

El objeto de este artículo es revisar sistemáticamente la epidemiología y microbiología clínicamente relevantes y los estudios clínicos terapéuticos relacionados con infecciones por Acinetobacter sp, con especial énfasis en ABPR.

\section{Estrategia de búsqueda}

Se revisaron todas las referencias citadas en MEDLINE y LILACS a enero de 2005, considerando términos claves como Acinetobacter baumannii, antimicrobial resistance, colistin y sulbactam. Se incluyó además la información de los resúmenes de conferencias como la Interscience Conference on Antimicrobial Agents and Chemotherapy (ICAAC), el Meeting of Infectious Diseases Society of America (IDSA) y el European Congress of Clinical Microbiology and Infectious Diseases (ECCMID), desde 2003 a la fecha. Se obtuvo reseña adicional de Internet de revistas con publicación electrónica adelantada y de otros documentos de acceso libre. Finalmente se consultó también la base de datos farmacéutica comercial Micromedex.

\section{Microbiología}

Acinetobacter sp engloba cocobacilos gram negativos, oxidasa negativos, no fermentadores, no esporulados y aerobios estrictos ${ }^{28}$. Se encuentra ampliamente disperso en la naturaleza, mayoritariamente en agua y suelo. Se ha aislado en personas sanas a partir de la piel, faringe y varias otras localizaciones. El género Acinetobacter se clasificaba antiguamente bajo unos quince nombres diferentes incluyendo Bacterium anitratum, Herellea vaginicola, Mima polymorpha, Achromobacter, Alcaligenes, Micrococcus 
calcoaceticus, B5W, Moraxella glucidolytica y Moraxella lwoffi. En 1954, Brisou y Prévot identificaron el género como Acinetobacter, con dos especies A. calcoaceticus y A. lwoffi. Sobre la base de recientes estudios genéticos se han identificado 19 especies diferentes, pero sólo 7 cuentan con nombre (calcoaceticus, baumannii, haemolyticus, junii, johnsonii, lwoffi, radioresistens ${ }^{29}$. Existe una estrecha relación entre el genoma de A. calcoaceticus y A. baumannii, de manera tal que a veces se les menciona como complejo Acinetobacter baumannii-calcoaceticus. En algunos reportes, estos aislados son referidos como A. calcoaceticus subespecies anitratus. Esta complicada historia taxonómica ha llevado tanto a diagnóstico como clasificaciones equivocadas de las especies en la práctica clínica ${ }^{16}$.

Acinetobacter sp se comporta generalmente como especies no virulentas pero, en pacientes críticamente enfermos, está bien documentado su rol patogénico. Los brotes de infecciones nosocomiales han sido comúnmente asociados con A. baumannii, otras especies son muy ra$\operatorname{ras}^{10,16}$.

\section{Epidemiología}

- Fuentes ambientales. Las especies de Acinetobacter pueden ser encontradas en objetos animados e inanimados. Crecen en casi todas las muestras de suelos y agua fresca ${ }^{16}$. En el medio hospitalario, estos microorganismos han sido aislados de humidificadores, equipos de ventilación, la piel del personal de salud, colchones, cojines y otros equipamientos ${ }^{10,28,30-35}$. Se ha reportado sobrevida en superficies secas mayor a 7 días para $A$. lwoffi y mayor a 25 días para A. baumannii. Acinetobacter calcoaceticus sobrevive hasta 13 días en superficies de formica ${ }^{36}$. Comparativamente, otros bacilos gramnegativos sobreviven sólo pocos días ${ }^{37}$, por ejemplo Escherichia coli sobrevive hasta 24 horas y Pseudomonas aeruginosa menos de 24 horas, mientras que Staphylococcus aureus persiste hasta 7 días en superficies de formica. La persistencia de las especies de Acinetobacter en las superficies medioambientales es su característica más distintiva entre los patógenos nosocomiales, explicando su mayor patogenicidad entre pacientes hospitalizados.

- Portación humana. Acinetobacter sp es parte de la microbiota cutánea. El 31\% del personal de salud es portador de bacilos gramnegativos en sus manos. Los microorganismos más co- múnmente aislados de este personal son Enterobacter sp (16,5\%) y Acinetobacter $\mathrm{sp}$ $(7,5 \%)^{32}$. Cuando se analiza la portación de especies de Acinetobacter comparando entre el personal sanitario que maneja directamente pacientes y los que no lo hacen, es más común esta portación entre estos últimos ${ }^{32,33}$. En otro estudio, un tercio de los trabajadores sanitarios (enfermeras y kinesiólogos) presentaron colonización transitoria por A calcoaceticus en sus manos. La faringe, vagina y recto son sitios excepcionales de colonización ${ }^{38}$. Tanto la persistencia sobre superficies secas como su presencia en la piel del personal sanitario, contribuyen a la transmisión cruzada entre pacientes. De esta manera, para prevenir o minimizar potenciales brotes, es esencial el cumplimiento de las medidas de óptimo control de infecciones.

\section{Factores de riesgo}

Las especies de Acinetobacter se consideran generalmente microorganismos de baja virulencia, salvo en pacientes críticamente enfermos o inmunocomprometidos ${ }^{16}$. Estos microorganismos se asocian más a menudo con infecciones nosocomiales que comunitarias. En regiones tropicales se han reportado, con alguna frecuencia, neumonías adquiridas en la comunidad, que comúnmente se presentan en meses húmedos $\mathrm{y}$ cálidos ${ }^{10,39}$.

La identificación de factores de riesgo es importante para el desarrollo de medidas de prevención de colonización e infección. Los múltiples factores identificados para la adquisición de infecciones por Acinetobacter incluyen enfermedad grave ${ }^{40}$, infección o sepsis previa ${ }^{14,40}$, ventilación mecánica prolongada, antibioterapia previa, colonización previa por Acinetobacter y estadía prolongada en unidad de cuidado intensivo ${ }^{10,40-42}$.

Se ha asociado el uso previo de antimicrobianos con la colonización e infección por Acinetobacter, situación que refuerza la necesidad de un uso prudente de los antimicrobianos ${ }^{14,40,42-45}$. Otros factores de riesgo, como la ventilación prolongada y la estadía en UCI, no serían específicos para Acinetobacter sp, sino que más bien estarían relacionados a la enfermedad subyacente del paciente. Por ejemplo, diversos factores de riesgo para infecciones del torrente sanguíneo por Acinetobacter son indistinguibles de los asociados con bacteriemias debidas a otros bacilos gramnegativos. Cuando se comparan otros factores de riesgo para bacteriemias por bacilos gramnegativos y Acinetobacter sp, tales como presencia de dispositivos intravasculares, nutri- 
ción parenteral o neutropenia, no se encuentran diferencias significativas ${ }^{41}$.

\section{Brotes nosocomiales}

Como se discutió previamente, se han reportado numerosos brotes nosocomiales causados por Acinetobacter. Estos se han asociado con contaminación de equipos de ventilación, colchones, cojines y humidificadores, y con el abuso de antimicrobianos específicos ${ }^{30,31,34,35,46}$. A menudo estos brotes exhiben patrones de multiresistencia, lo que hace muy dificultosa su erradicación desde el paciente y desde el medioambiente. Los patrones de resistencia varían de región en región, en algunas áreas se reporta susceptibilidad exclusiva a carbapenémicos, mientras que en otras la resistencia comprende todos los antimicrobianos comercialmente disponibles ${ }^{17,18,23}$. En los años recientes la incidencia mundial de $A$. baumannii resistente a carbapenémicos ha aumentado paulatinamente ${ }^{3,18,23,46-48}$.

\section{Vigilancia}

Las infecciones por A. baumannii están documentadas mundialmente, su susceptibilidad antimicrobiana varía de país en país, destacando algunas regiones con alta prevalencia de $A$. baumannii multi-resistente. Las tendencias de resistencia de A. baumannii a antimicrobianos han sido evaluada en dos estudios de vigilancia epidemiológica. La base datos del estudio SENTRY entre 1997 y 1999 muestra una mayor susceptibilidad de los aislados de Norteamérica (Canadá y E.U.A.) respecto de los latinoamericanos. Se incluyeron aislados únicos y seriados de sangre, secreciones respiratorias, piel y tejidos blandos y tracto urinario ${ }^{3}$.

Sader y cols comunicaron en el año 2004 diferencias geográficas significativas del SENTRY en el perfil de susceptibilidad de $A$. baumannii ${ }^{49}$. En muestras de infecciones de torrente sanguíneo, $75 \%$ de las cepas se mostró susceptible a ampicilina/sulbactam en Norteamérica versus 51,4 y $47,8 \%$ en Europa y Latinoamérica, respectivamente. La susceptibilidad a amikacina fue 82,3; 62,1 y $53,1 \%$ en el mismo orden. En Europa existe menor susceptibilidad a imipenem $(74,3 \%)$ versus Norteamérica $(87,9 \%)$ y Latinoamérica $(91,2 \%)$. Polimixina B muestra porcentajes similares de 97,6\% en Norteamérica, 98,9\% en Europa y $98,2 \%$ en Latinoamérica.

La base de datos $\mathrm{SCOPE}^{41}$ que incluye 49 hospitales estadounidenses muestra una disminución de la susceptibilidad de A. baumannii a cefalosporinas y fluoroquinolonas. Si bien ambos estudios muestran que los carbapenémicos mantienen plena actividad entre los aislados incluidos (casi $100 \%$ son susceptibles), diversos reportes de A. baumannii resistentes a carbapenémicos se han informado en E.U.A., Canadá y Latinoamérica $^{3,17,18,46}$.

Una reseña actualizada (1997-2003) de la tendencia de susceptibilidad a antimicrobianos de A. baumannii en SENTRY Latinoamérica se detalla en la Tabla $2^{50,51}$.

En Chile, Silva y cols reportaron en 1999, en 123 cepas clínicas de A. baumannii, una resistencia de 37,4\% a ampicilina/sulbactam, 36,6\% a cefoperazona/sulbactam, 47,9\% a amikacina y $0 \%$ a imipemen ${ }^{52}$. Trucco y cols, en 45 cepas de A. baumannii evaluadas durante 2001, detectaron $30 \%$ de resistencia a ampicilina/sulbactam, $80 \%$ a cefoperazona/sulbactam, $47 \%$ a amikacina, $20 \%$ a cefepime, y $10 \%$ a imipenem ${ }^{53}$. Finalmente, en el estudio NPRS de 2002, que incluye cepas clínicas de pacientes en UCI de cuatro centros nacionales, se documentó resistencia a cefoperazona/sulbactam entre 21 y $78 \%$ y a imipenem entre 0 y $7 \%{ }^{54}$.

\section{Mecanismos de resistencia}

Diversos reportes han comunicado altas tasas de resistencia antimicrobiana en Acinetobacter $\mathrm{sp}$, sus patrones de resistencias varían según especies aisladas y zona geográfica. Seifert y cols $^{55}$ informaron que A. baumannii es generalmente más resistente que $A$. lwoffi. Esto también se ha notado al revisar la base de datos SCOPE donde los aislados de A. baumannii son generalmente más resistentes que las especies no baumannii (por ej.: radioresitens, junni, lwoffi) ${ }^{41}$. El género Acinetobacter tiene una rápida tendencia a desarrollar resistencia antimicrobiana ${ }^{16}$. Los mecanismos de resistencia contemplan alteraciones de las proteínas ligadoras de penicilinas (PBP), disminución de la permeabilidad de la membrana externa, mutaciones de los sitios blanco e inactivación por enzimas modificantes ${ }^{56}$. Dado que Acinetobacter sp son microorganismos gramnegativos, poseen una membrana externa adicional que actúa como barrera de permeación ${ }^{57,58}$. El transporte a través de la membrana externa está mediado por porinas que producen canales llenos de agua por difusión de moléculas hidrofílicas (por ej.: $\beta$-lactámicos, carbapenémicos). Algunos reportes sugieren que la expresión reducida o mutación de porinas estarían asociadas a resistencia a carbapenémicos ${ }^{59}$. En la Tabla 3 se enumeran los diferentes mecanismos de resistencia en A. baumannii. 
Tabla 2. Susceptibilidad a antimicrobianos de Acinetobacter baumannii en Latinoamérica según estudio SENTRY 1997-2003 ${ }^{47,48}$

\begin{tabular}{|c|c|c|c|c|c|c|c|c|c|}
\hline \multirow[t]{2}{*}{ Antimicrobianos } & \multicolumn{7}{|c|}{$\begin{array}{l}\text { Porcentaje de susceptibles por año } \\
\text { (número de cepas testeadas) }\end{array}$} & \multicolumn{2}{|c|}{$\underset{(\mu \mathrm{g} / \mathrm{ml})}{\mathrm{CIM}}$} \\
\hline & $\begin{array}{l}1997 \\
(193)\end{array}$ & $\begin{array}{l}1998 \\
(215)\end{array}$ & $\begin{array}{l}1999 \\
(129)\end{array}$ & $\begin{array}{l}2000 \\
(123)\end{array}$ & $\begin{array}{l}2001 \\
(166)\end{array}$ & $\begin{array}{l}2002-2003 \\
(295)\end{array}$ & $\begin{array}{l}\text { Total } \\
\left(^{(826)}\right)^{\&} \\
(\mathbf{1 . 1 2 1})\end{array}$ & $\mathrm{CIM}_{50}$ & $\mathrm{CIM}_{90}$ \\
\hline Meropenem & 91,3 & 87,0 & 89,1 & 82,9 & 81,9 & - & $86,8^{\&}$ & 2 & $>8$ \\
\hline Imipenem & 91,2 & 87,0 & 88,4 & 82,9 & 83,7 & 84,0 & 85,9 & 1 & $>8$ \\
\hline Cefepime & 33,7 & 27,4 & 48,8 & 38,2 & 30,4 & 41,0 & 37,2 & $>16$ & $>16$ \\
\hline Ceftazidima & 29,0 & 17,7 & 37,2 & 35,0 & 45,8 & - & $28,5^{\&}$ & $>16$ & $>16$ \\
\hline Ampicilina/ sulbactam & - & - & - & - & - & 47,0 & 47,0 & 16 & - \\
\hline Piperazilina/ tazobactam & 24,9 & 19,5 & 36,4 & 30,1 & 27,7 & - & $26,6^{\&}$ & $>64$ & $>64$ \\
\hline Ticarcilina/ clavulanato & 19,2 & 20,0 & 32,6 & 28,5 & 23,5 & - & $24,8^{\&}$ & $>128$ & $>128$ \\
\hline Ciprofloxacina & 27,5 & 29,3 & 34,9 & 35,8 & 28,3 & - & $30,5^{\&}$ & 1 & $>4$ \\
\hline Levofloxacina & 29,0 & 30,7 & 37,2 & 39,8 & 28,9 & 42,0 & 35,7 & $>4$ & $>4$ \\
\hline Tetraciclina & 68,4 & 49,8 & 52,7 & 46,7 & 33,7 & - & $50,9^{\&}$ & 8 & $>8$ \\
\hline Amikacina & 35,8 & 27,0 & 37,2 & 35,0 & 38,0 & 46,0 & 37,9 & $>32$ & $>32$ \\
\hline Gentamicina & 33,7 & 30,2 & 40,3 & 31,7 & 30,7 & - & $32,9^{*}$ & $>8$ & $>8$ \\
\hline Polimixina B & - & - & - & - & 96,4 & 99,0 & $97,7^{*}$ & $\leq 1$ & 2 \\
\hline
\end{tabular}

*: Las cepas con CIM $\leq 2 \mu \mathrm{g} / \mathrm{ml}$ se consideraron susceptibles a polimixina B.

$\&$ : Sin datos 2002-2003.

La membrana externa de $A$. baumannii es menos permeable a los antimicrobianos que la membrana externa de E. coli. Según Vila ${ }^{60}$ al analizar la permeabilidad de la membrana externa de $A$. baumannii se detecta que el coeficiente de permeabilidad a las cefalosporinas es de 2 a 7 veces menor que el que presenta $P$. aeruginosa para los mismos $\beta$-lactámicos. Por todo ello, se sugiere que una causa de la resistencia intrínseca que presenta $A$. baumannii a los antimicrobianos puede ser atribuida a la presencia de un escaso número de porinas que además poseen un tamaño de poro pequeño. Sin embargo, no se descarta que la expresión constitutiva a niveles bajos de uno o varios sistemas de expulsión activa contribuya a la resistencia intrínseca basal que presenta A. baumannii a diversos agentes antimicrobia$\operatorname{nos}^{61}$.

Los mecanismos de resistencia a $\beta$-lactámicos involucran la producción de $\beta$-lactamasas cromosomales o plasmidiales, alteraciones de las PBP y disminución de la permeabilidad a $\beta$-lactámicos de la membrana externa ${ }^{59}$. Las $\beta$-lactamasas se dividen en tres grupos: clase A de Ambler (penicilinasas), clase B de Ambler (metaloenzimas) y clase D de Ambler (oxacilinasas) ${ }^{62}$. Estas enzimas hidrolizan, al menos parcialmente, carbapenémicos y otros $\beta$-lactámicos. Las $\beta$ lactamasas de clase A se han reportado raramen- te en Acinetobacter sp y Pseudomonas $\mathrm{sp}^{63,64}$. Se han descrito entre las Enterobacteriaceas (p ej: E. coli, Klebsiella sp) $\beta$-lactamasas de espectro extendido (BLEE), que inusualmente se asocian a $P$. aeruginosa o Acinetobacter sp. Los microorganismos poseedores de BLEE son distintivamente inhibidos por el acido clavulánico y son resistentes a los oximino- $\beta$-lactámicos (por ejemplo cefotaxima, ceftriaxona, cefpodoxima o ceftazidima). La mayoría de las BLEE encontradas en Enterobacteriaceas se relacionan con $\beta$-lactamasas tipo TEM y $\mathrm{SHV}^{65}$. En Turquía, Corea y Francia, se ha identificado recientemente en $A$. baumannii una nueva BLEE (PER-1) no relacionada con las BLEE encontradas en E. coli y Klebsiella $\mathrm{sp}^{66-69}$. Carbonne y cols ${ }^{70}$ reportaron el primer brote nosocomial con VEB-1, otra nueva BLEE sólo reportada anteriormente en Enterobacteriaceas y $P$. aeruginosa en el sudeste asiático.

Las $\beta$-lactamasas clase B son enzimas dependientes de zinc cuya actividad es inhibida por EDTA, pero no por carbapenémicos o inhibidores de $\beta$-lactamasas como el acido clavulánico, tazonam y sulbactam. Estas metalo-enzimas constituyen un mecanismo de resistencia adquirida de localización cromosomal o plasmidial ${ }^{62,71}$. Las oxacilinasas, $\beta$-lactamasas de clase $\mathrm{D}$, también se encuentran en especies de Acinetobacter; existen múltiples subtipos que tienen diversos patro- 
nes de hidrólisis pero, en general, las oxacilinasas hidrolizan débilmente a carbapenémicos (imipenem y meropenem) y no hidrolizan cefalosporinas de espectro extendido ni aztreonam. Su acción hidrolítica es inhibida por ácido clavulánico ${ }^{65,72}$.
Ocasionalmente los aminoglucósidos son empleados combinados con $\beta$-lactámicos para mejorar su actividad bactericida. La resistencia a aminoglucósidos está mediada por tres mecanismos: alteración del sitio de acción ribosomal,

Tabla 3. Mecanismos relevantes de resistencia a antimicrobianos en Acinetobacter baumannii ${ }^{12,52-71}$

\begin{tabular}{|c|c|c|c|c|}
\hline $\begin{array}{l}\text { Mecanismos de } \\
\text { resistencia }\end{array}$ & Clase molecular & Descripción & $\begin{array}{l}\text { Sustratos } \\
\text { preferentes }\end{array}$ & Comentarios \\
\hline \multirow[t]{5}{*}{$\beta$-lactamasas } & Clase A de Ambler & $\begin{array}{l}\text { De espectro } \\
\text { ampliado: } \\
\text { TEM-1, TEM-2 }\end{array}$ & Penicilinas & \\
\hline & & $\begin{array}{l}\text { De espectro } \\
\text { extendido (BLEE): } \\
\text { PER-1, VEB-1. }\end{array}$ & 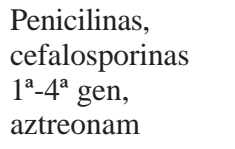 & \\
\hline & Clase B de Ambler & $\begin{array}{l}\text { Metalo- } \beta \text { - } \\
\text { lactamasas: } \\
\text { IMP-1, IMP-2, } \\
\text { IMP-4, IMP-5, } \\
\text { VIM-1, VIM-2, } \\
\text { blaSPM }\end{array}$ & $\begin{array}{l}\text { Penicilinas, } \\
\text { cefalosporinas } \\
1^{\mathrm{a}}-4^{\mathrm{a}} \text { gen, } \\
\text { carbapenémicos, } \\
\text { no aztreonam }\end{array}$ & Codificadas por plásmidos \\
\hline & Clase C de Ambler & $\begin{array}{l}\text { Cefalosporinasas: } \\
\text { AmpC, CARB-5 }\end{array}$ & $\begin{array}{l}\text { Penicilinas, } \\
\text { cefalosporinas }\end{array}$ & $\begin{array}{l}\text { El } 98 \% \text { de las cepas produce } \\
\text { AmpC, es inducida o des- } \\
\text { reprimida por exposición a } \\
\text { antibacterianos }\end{array}$ \\
\hline & Clase D de Ambler & $\begin{array}{l}\text { Oxacilinasas: } \\
\text { OXA-23, OXA-24, } \\
\text { OXA-25, OXA-26, } \\
\text { OXA-27, OXA-40, } \\
\text { OXA-49, OXA-51, } \\
\text { OXA-58 }\end{array}$ & $\begin{array}{l}\text { Penicilinas, } \\
\text { cefalosporinas } \\
\text { variable, } \\
\text { carbapenémicos, } \\
\text { no aztreonam }\end{array}$ & \\
\hline $\begin{array}{l}\text { Alteración de PBP } \\
\text { y porinas de } \\
\text { membrana (PME) }\end{array}$ & & $\begin{array}{l}\text { Enzima ligadora } \\
\text { de penicilina } \\
\text { no identificada }\end{array}$ & Carbapenémicos & $\begin{array}{l}\text { Generalmente se asocia la } \\
\text { mutación de porinas con } \\
\text { sobreproducción de AmpC }\end{array}$ \\
\hline & & $\begin{array}{l}\text { PME } 29 \mathrm{kDa} \\
\text { PME 33-36 KDA }\end{array}$ & & \\
\hline \multirow{3}{*}{$\begin{array}{l}\text { Inactivación } \\
\text { enzimática del } \\
\text { antimicrobiano }\end{array}$} & $\mathrm{N}$-acetiltransferasas & $\begin{array}{l}\text { Enzimas acetiladoras: } \\
\text { AAC I-V }\end{array}$ & Aminoglucósidos & \\
\hline & $\begin{array}{l}\text { 0-nucleotidil- } \\
\text { transferasas }\end{array}$ & $\begin{array}{l}\text { Enzimas } \\
\text { adeniladoras: } \\
\text { ANT, AAD }\end{array}$ & & \\
\hline & 0 -fosfotransferasas & $\begin{array}{l}\text { Enzimas } \\
\text { fosforiladoras: } \\
\text { APH I-IV }\end{array}$ & & \\
\hline \multirow{2}{*}{$\begin{array}{l}\text { Mutación ADN } \\
\text { polimerasas }\end{array}$} & ADN-girasa & gyr-A & Fluroquinolonas & \\
\hline & Topoisomerasa IV & par-C & & \\
\hline
\end{tabular}


reducción de la captura y modificación enzimática del antimicrobiano ${ }^{73}$. La alteración del blanco ribosomal no es significativa pues sólo afecta a estreptomicina y espectinomicina. El segundo mecanismo es bastante común en las especies de Acinetobacter, pero el tercer mecanismo es el que da cuenta de la mayoría de los aislados resistentes. Las enzimas modificadoras, tales como Ofosfotransferasas, O-nucleotidil-transferasas y $\mathrm{N}$-acetiltransferasas, están mediadas primariamente por plásmidos y trasposones que pueden jugar un importante rol en la diseminación de resistencia. Tales enzimas pueden también tener localización cromosomal. Cada una tiene un sustrato diferente que confiere a la bacteria un perfil específico de resistencia ${ }^{73}$.

Las fluoroquinolonas tienen una buena actividad sobre Acinetobacter sp, pero la resistencia está aumentando ${ }^{3,17,18}$. Los mecanismos de resistencia se relacionan con mutaciones de la ADNgirasa y la topo-isomerasa IV, blancos específicos de tales antibacterianos ${ }^{74}$. La ADN-girasa está compuesta de dos subunidades, codificadas por los genes gyr A y gyr B. La topo-isomerasa IV es estructuralmente similar a la ADN-girasa, pero es un blanco secundario de las fluoroquinolonas. Las dos subunidades de la topoisomerasa IV están codificadas por los genes par $\mathrm{C}$ y par $\mathrm{E}^{74}$. La resistencia en Acinetobacter $\mathrm{sp}$ está mediada por mutaciones en los genes gyr A y par $\mathrm{C}^{74}$. En los aislados de A. baumannii con una o ambas mutaciones, ciprofloxacina ha reducido susceptibilidad comparada con gatifloxacina, gemifloxacina, levofloxacina, moxifloxacina y trovafloxacina ${ }^{75}$. Se han descrito otros mecanismos de resistencia, tales como bombas de eflujo e influjo, pero su rol no ha sido todavía dilucidado respecto de las fluoroquinolonas ${ }^{76}$.

\section{Modelos experimentales}

La emergencia de Acinetobacter sp como un significativo patógeno nosocomial y las tendencias actuales que muestran un aumento de aislados de Acinetobacter resistentes a los antimicrobianos requieren la búsqueda de nuevas terapias. Lamentablemente, existen pocos modelos adecuados de infección por A. baumannii en animales.

Un estudio comparó la actividad de colistín, sulbactam, imipenem, tobramicina y rifampicina contra aislados de $A$. baumannii en un modelo de neumonía murina ${ }^{77}$. Se utilizaron tres cepas diferentes de A. baumannii con diferentes CIMs a imipenem $(1,8,512 \mu \mathrm{g} / \mathrm{ml})$ y otros antimicrobianos. Las tres cepas fueron susceptibles a colistín (CIM 0,5 $\mu \mathrm{g} / \mathrm{ml}$ ). Cuando se evaluó el impacto en el conteo bacteriano pulmonar de cepas susceptibles o medianamente susceptibles a imipenem, la terapia más eficaz fue el mismo imipenem y el sulbactam. En el modelo de neumonía murina, colistín mostró tener la menor actividad bactericida de todos los antimicrobianos testeados $(\mathrm{p}<0,05)$.

En este mismo modelo animal se compararon diversas terapias combinadas contra A. baumannii ( $\beta$-lactámicos, inhibidores de $\beta$-lactamasas, rifampicina $)^{78}$, se utilizaron dos cepas de aislados clínicos de A. baumannii: una productora de cefalosporinasa y otra PMR. Las cepas con cefalosporinasa fueron susceptibles a imipenem (CIM 0,5 $\mu \mathrm{g} / \mathrm{ml})$, ticarcilina $(32 \mu \mathrm{g} / \mathrm{ml})$ y sulbactam (CIM 0,5 $\mu \mathrm{g} / \mathrm{ml}$ ), pero resistentes a aminoglucósidos y fluoroquinolonas. La cepa MR tuvo una CIM de $8 \mu \mathrm{g} / \mathrm{ml}$ para imipenem y fue resistente a todos los otros antimicrobianos, con excepción de rifampicina (CIM $4 \mu \mathrm{g} / \mathrm{ml})$. En este modelo, sulbactam e imipenem individualmente produjeron un efecto bactericida sobre las cepas productoras de cefalosporinasa. La combinación de imipenem/rifampicina y ticarcilina/clavulanato/ sulbactam fueron bactericidas, pero no más efectivas que los agentes individuales. Todos los agentes prolongaron la sobrevida en los ratones tratados versus los controles $(\mathrm{p}<0,001)$, pero ticarcilina/clavulanato/sulbactam obtuvo la mejor tasa de sobrevida.

Las cepas MR obtuvieron diferentes resultados. Imipenem y rifampicina solas, al igual que las combinaciones imipenem/rifampicina, rifampicina/sulbactam, imipenem/sulbactam, ticarcilina/sulbactam y rifampicina/ticarcilina/ clavulanato/sulbactam, obtuvieron excelente acción bactericida. Empero, los regímenes combinados no fueron mejores que un único agente eficaz. Rifampicina prolongó la sobrevida significativamente mejor que imipenem $(\mathrm{p}=0,01)$. Todas las combinaciones mejoraron la sobrevida comparadas con los controles $(\mathrm{p}<0,01)$, pero los regímenes que contenían rifampicina obtuvieron mejores tasas de sobrevida ${ }^{78}$.

Otro reciente estudio en el modelo de neumonía murina, comparó la actividad de imipenem, sulbactam y rifampicina como monoterapia o en combinación frente a AB-MR ${ }^{79}$. La mortalidad del grupo control (69\%) fue reducida en los grupos con imipenem/sulbactam $(14 \%, \mathrm{p}=0,006)$ y rifampicina $(28 \%, \mathrm{p}=0,03)$. La concentración (UFC/gr) de A. baumannii en el pulmón se redujo significativamente en los grupos de imipenem/ rifampicina $(\mathrm{p}=0,04)$ y rifampicina $(\mathrm{p}=0,01)$, sulbactam con imipenem o rifampicina redujo no significativamente este parámetro e imipenem o 
sulbactam solos no disminuyeron el conteo de colonias. Sólo rifampicina permitió una esterilización significativa de los hemocultivos versus control (78 vs 27\%, p =0,01). Según esto, se concluye que la monoterapia con rifampicina o la combinación de imipenem/sulbactam sería eficaz en el tratamiento de la neumonía experimental por AB-MR.

También se ha evaluado en el modelo de neumonía murina la actividad de levofloxacina como terapia única o en combinación con imipenem o amikacina ${ }^{80}$; para ello se utilizaron dos cepas de aislados clínicos, una con CIM a levofloxacina de $0,06 \mu \mathrm{g} / \mathrm{ml}$ y otra con CIM de $4 \mu \mathrm{g} / \mathrm{ml}$. Ambas cepas fueron sensibles a imipenem y amikacina. Levofloxacina sola o combinada con imipenem y amikacina redujo el conteo bacteriano pulmonar versus sus controles, pero la terapia combinada no fue superior a la monoterapia.

En otro estudio de terapia combinada de infecciones por A. baumannii en neumonía murina, se evaluó el uso de imipenem, doxiciclina y amikacina solos o combinados ${ }^{81}$. En este estudio, la cepa elegida era susceptible a imipenem (CIM 0,12 $\mu \mathrm{g} / \mathrm{ml})$, amikacina $(2 \mu \mathrm{g} / \mathrm{ml})$ y doxiciclina $(0,5$ $\mu \mathrm{g} / \mathrm{ml})$. Los grupos tratados con imipenem solo, imipenem/amikacina, imipenem/doxiciclina o doxiciclina/amikacina tuvieron mejor aclaramiento bacteriano pulmonar que los grupos tratados solamente con doxiciclina o amikacina $(\mathrm{p}<0,05)$. No hubo diferencia en el aclaramiento bacteriano pulmonar entre los grupos de imipenem, imipenem/ amikacina o doxiciclina/amikacina $(2,42$ vs 2,7 vs 1,5 UFC/gr, respectivamente). Si bien las tasas de sobrevida en los grupos tratados fueron mayores que en los controles, no se vieron diferencias entre los grupos de terapia combinada.

El inhibidor de $\beta$-lactamasas sulbactam se han evaluado en modelos experimentales de neumonía murina y de endocarditis en conejos $^{82}$. Se evaluaron dos cepas de A. baumannii; la cepa utilizada en el modelo de endocarditis tenía susceptibilidad intermedia a sulbactam e imipenem. En el modelo de neumonía, se evaluaron dos dosis de sulbactam comparados con imipenem; en el modelo de endocarditis sólo se evaluó una dosis de sulbactam. Las tasas de sobrevida fueron similares entre los grupos tratados y mejores que en los respectivos controles. Los grupos con alta dosis de sulbactam e imipenem obtuvieron mejor aclaramiento bacteriano pulmonar $(1,95 \mathrm{y}$ $1,25 \mathrm{UFC} / \mathrm{gr}$ respectivamente) que el grupo con baja dosis de sulbactam $(3,68$ UFC/gr, $\mathrm{p}<0,05)$. En el modelo de endocarditis, ambos grupos tratados mostraron mayor esterilización de las válvulas cardíacas que los controles $(\mathrm{p}<0,05)$, pero no existieron diferencias entre los tratados y no tratados respecto de la esterilización de los hemocultivos.

La combinación de cefoperazona/sulbactam, junto a imipenem y meropenem, han sido evaluados en un modelo de absceso de muslo en ratas $^{83}$. Se inocularon 18 cepas de aislados clínicos de $A$. baumannii, todas susceptibles a los antibacterianos testeados, en 54 ratas. Un primer grupo recibió imipenem, otro meropenem y un tercero cefoperazona/sulbactam. Luego de cuatro días de tratamiento se sacrificaron las ratas y se procesó el material obtenido de los abscesos mediante conteo de UFC/gr más búsqueda de mutantes resistentes. La media de UFC/gr (media \pm desviación estándar x $\left.10^{4}\right)$ fue de 9,14 $(25,24)$, $2,11(3,78), 1,20(1,70)$ en los grupos de imipenem ( $\mathrm{n}=17)$, meropenem $(\mathrm{n}=18)$, y cefoperazona/sulbactam $(\mathrm{n}=17)$, respectivamente. No hubo diferencias significativas. Tampoco se detectaron mutantes resistentes. Según este modelo cefoperazona/sulbactam tendría una eficacia bactericida a carbapenémicos.

Los estudios in vivo discutidos anteriormente plantean la necesidad de realizar estudios clínicos para identificar los regímenes más apropiados en el tratamiento de infecciones por Acinetobacter.

\section{Estudios clínicos}

Acinetobacter sp puede causar diversas infecciones como neumonía nosocomial, bacteriemia, infecciones del tracto urinario, meningitis secundaria y, más raramente, endocarditis. Lamentablemente, como la resistencia se ha incrementado, pocos antimicrobianos pueden ser usados confiablemente para un tratamiento efectivo de infecciones por AB-PMR. Puesto que escasos antimicrobianos son consistentemente eficaces en la terapia de infecciones nosocomiales por Acinetobacter, la búsqueda de nuevos fármacos y la reevaluación de antiguos agentes son prioritarias. Se han comunicado recientes reportes de éxito para el tratamiento de estas infecciones en un limitado número de estudio clínicos no aleatorios con dos antiguos agentes: colistín y sulbactam. Los estudios detallados a continuación, se resumen en la Tabla 4.

\section{Colistín}

El colistín o colistina es un polipéptido catíonico integrante de la familia de las polimixinas (colistimetato - sulfometato de colistina - o polimixina E). Las polimixinas fueron descubiertas en 1947, reconociéndose cinco componentes 


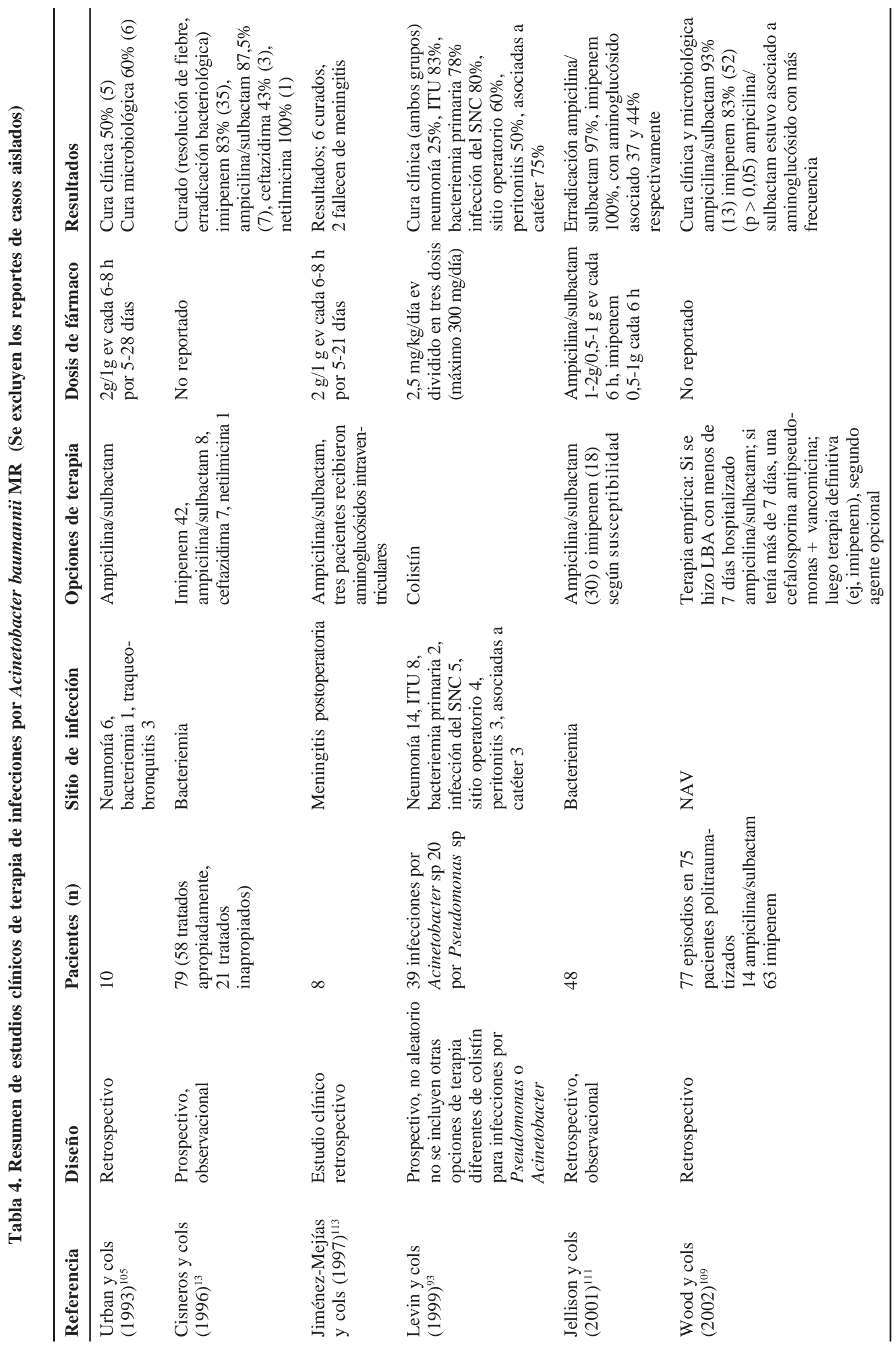




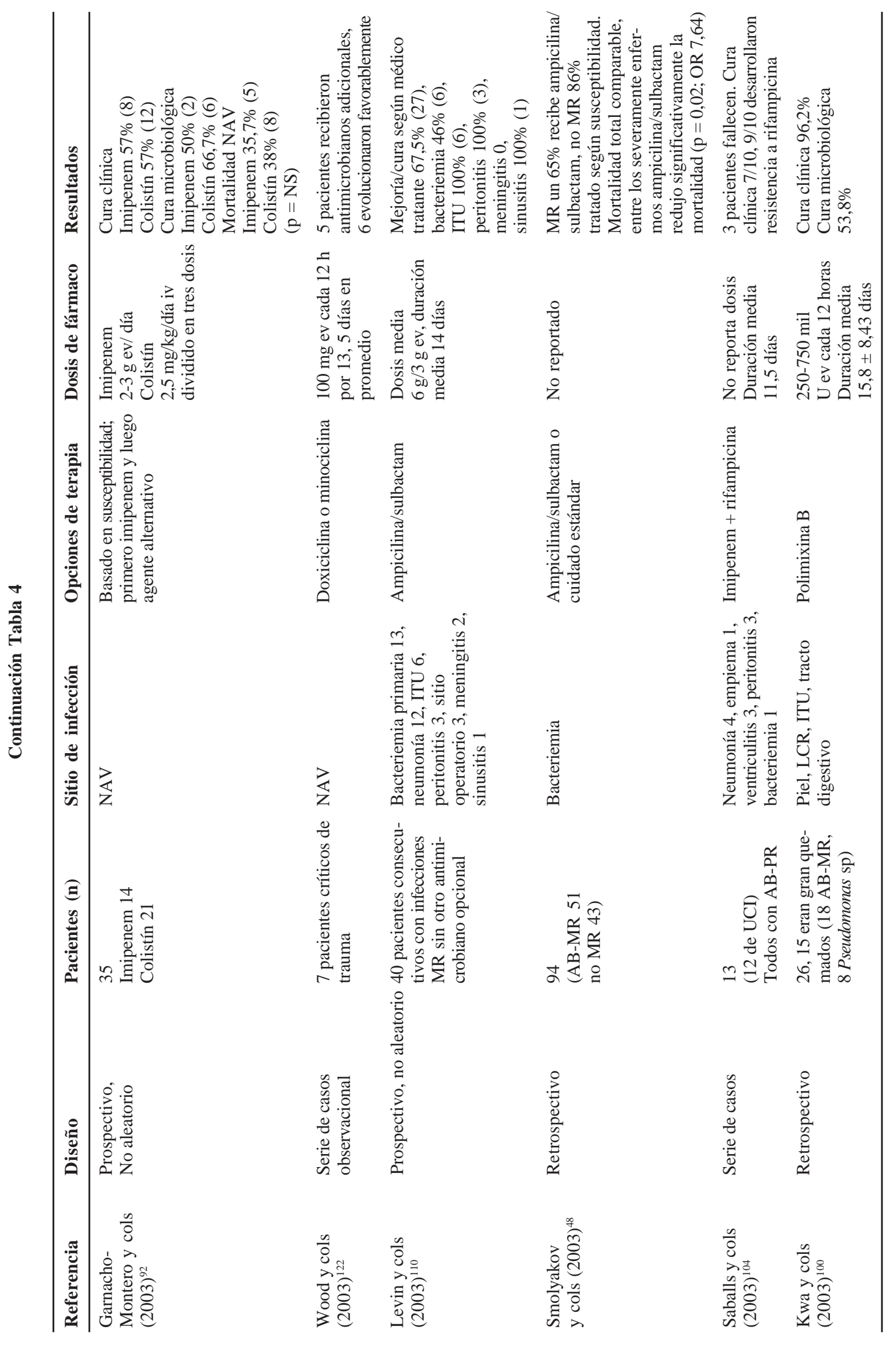




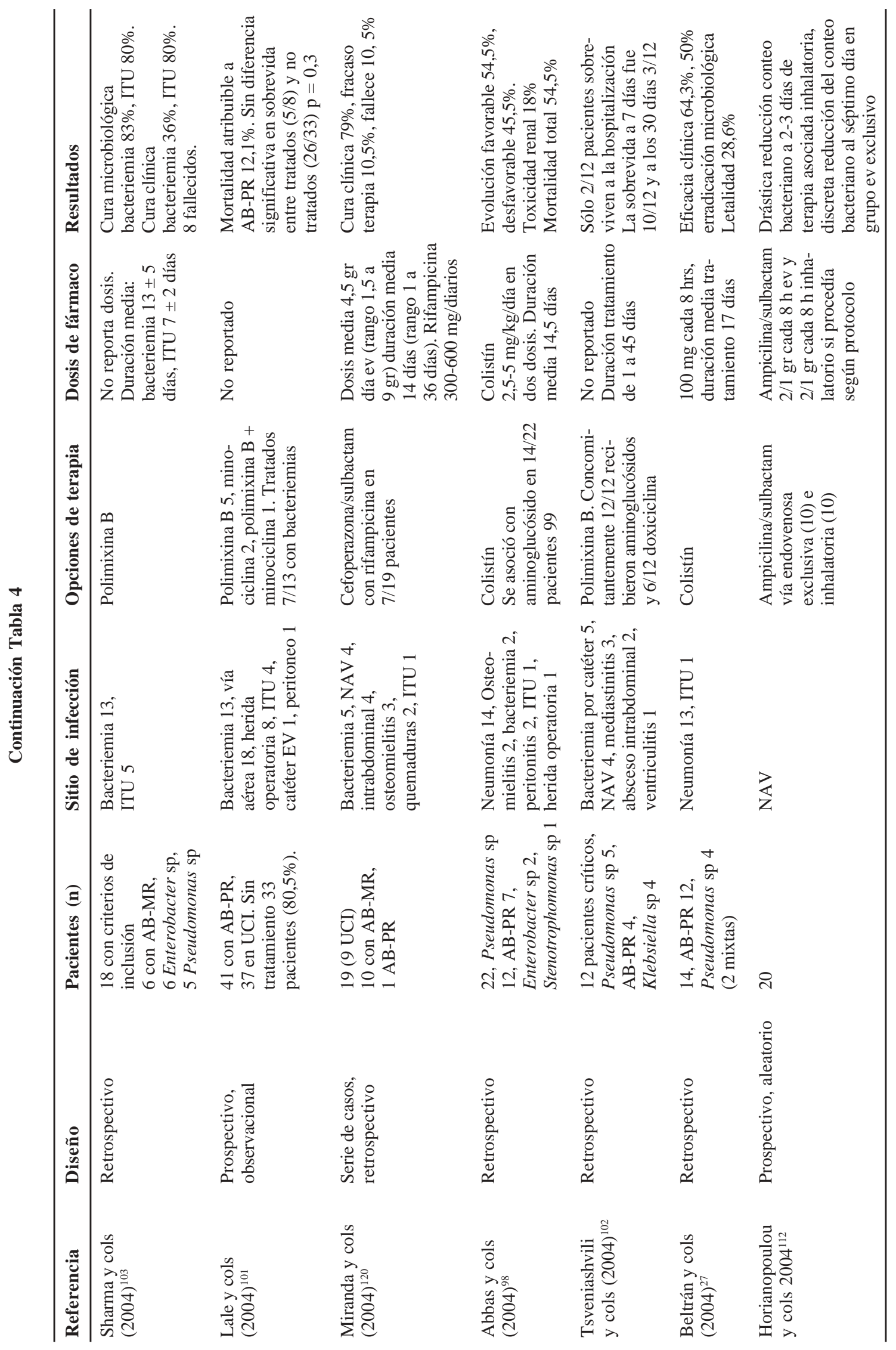




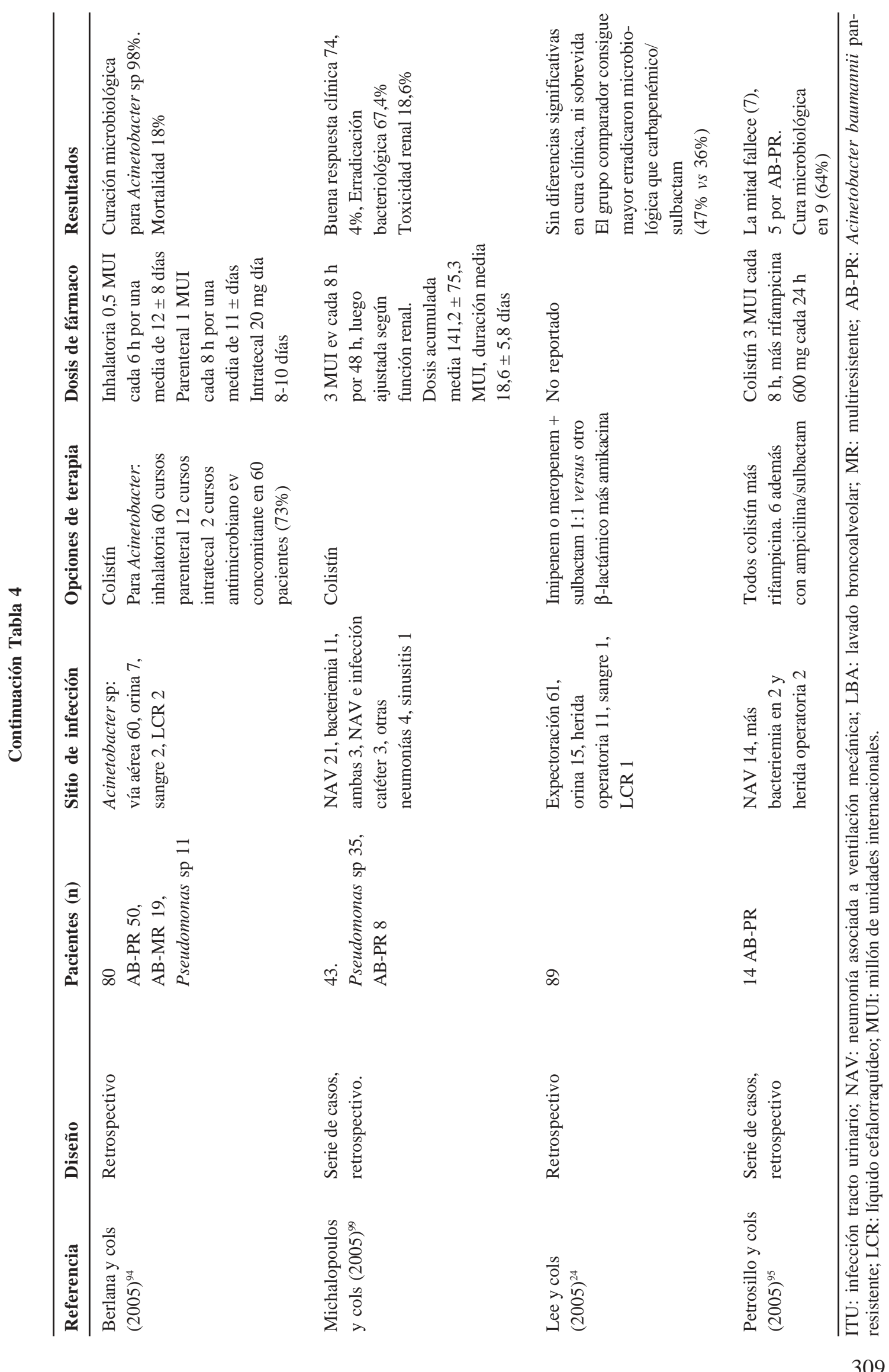


(polimixinas A-E $)^{84}$. Sólo polimixina B y E han sido utilizadas en clínica. Colistín fue descrito por Koyama en 1949, sintetizado por el Bacillus polymyxa subespecie colistinus ${ }^{85}$. Este agente se utilizó originalmente durante las décadas del sesenta y setenta, pero dada su nefro y neurotoxicidad su prescripción era infrecuente. Su rol en el manejo de infecciones graves por bacilos gramnegativos se ha reposicionado gracias a su potente actividad contra estas bacterias. La mayoría de los estudios clínicos que investigan el uso de polimixinas frente a microorganismos multiresistentes utilizan más bien colistín que polimixina $\mathrm{B}^{86,87}$. Se componen de un anillo peptídico policatíonionico que contiene 10 aminoácidos y una cadena lateral de ácidos grasos. Ambos agentes son bactericidas, al actuar sobre la pared celular bacteriana alteran su permeabilidad, llevando a la muerte celular por lisis. Son moléculas anfipáticas, lo que permite su distribución entre compartimientos acuosos y no acuosos. Se absorben pobremente en el tracto gastrointestinal.

El colistimetato sódico no esta disponible como producto parenteral en Chile, pero puede ser importado desde Argentina (Alficetin ${ }^{\circledR}$ de Bristol Myers Squibb, frasco ampolla $100 \mathrm{mg}$ ). El sulfato de colistín sólo esta disponible para el uso oral o tópico ${ }^{86}$. Dos recientes y estupendas artículos de $\mathrm{Li}^{84}$ y Falagas ${ }^{85}$ revisan exhaustivamente el rol de este antimicrobiano en el manejo de infecciones por bacilos gramnegativos multiresistentes.

Colistín se concentra en el hígado, riñón, músculo, corazón y pulmones, pero no penetra consistentemente la barrera hematoencefálica ante meninge inflamada. En dosis repetidas, colistín puede acumularse en los tejidos, desde los cuales luego difunde cuando el fármaco ha sido discontinuado. Su ruta primaria de excreción es el riñón; por lo mismo, la dosis debe ser reducida en pacientes con insuficiencia renal ${ }^{88}$. El rango de dosificación es de 2,5 a 5,0 mg/kg/día en pacientes con función renal normal, administrándose 2 a 4 veces al día ${ }^{86}$.

Los mayores efectos adversos de colistín son nefrotoxicidad, neurotoxicidad reversible y bloqueo neuromuscular. Puede causar un efecto tóxico directo que resulte en necrosis tubular aguda. Los efectos neurotóxicos incluyen parestesia perioral, ataxia, vértigo, disturbios visuales, confusión e inestabilidad vasomotora. Además puede causar bloqueo neuromuscular generador de falla respiratoria. Para evitar estos efectos indeseables, pudieran explorarse rutas de administración alternativas, como la vía inhalatoria e intraventricular. Colistín inhalatorio se ha utiliza- do para disminuir la colonización con agentes gramnegativos multi-resistentes en fibrosis quística ${ }^{89,90}$. El colistimetato sódico se ha utilizado exitosamente por administración intraventricular en ventriculitis debida a $A$. baumannii resistente a carbapenémicos ${ }^{91}$.

En un estudio prospectivo no aleatorio se comparó el tratamiento de la neumonía asociada a ventilador (NAV) debida a AB-MR con colistín endovenoso versus imipenem ${ }^{92}$. El diagnóstico microbiológico de NAV se basó en muestras de cepillo protegido o aspirado traqueal. En caso que A. baumannii fuese susceptible, se utilizó imipenem reservándose colistín para aquellos aislados sólo susceptibles a este fármaco. El objetivo primario de análisis evaluado fue la cura clínica de NAV. Se monitorizó diariamente la función renal y en los últimos días de terapia antimicrobiana se realizaron estudios electrofisiológicos en ambos grupos. Las características basales de ambos grupos (puntuación Apache II, diagnóstico primario, enfermedad de base) no tenían diferencias estadísticamente significativas. El 57\% de cada grupo finalizó tratamiento al considerarse que su NAV estaba curada. Las tasas de mortalidad intrahospitalaria fueron similares $61,9 \%$ (n 13) en el grupo de colistín y 64,2\% (n 9) para imipenem. Veinte pacientes en el grupo de colistín se sometieron a evaluación neurofisiológica. No se encontró evidencia de bloqueo neuromuscular pero la mitad de los pacientes tuvo neuropatía de enfermedad crítica. Este estudio demostraría que colistín es una opción eficaz para la NAV debida a AB-MR ${ }^{92}$.

Otro estudio evalúa el uso de colistín en aislados de $P$. aeruginosa y A. baumannii MR. Se identificaron pacientes con cepas sólo susceptibles a colistín de enero de 1993 a diciembre de $1994^{93}$. Hubo 60 infecciones en 59 pacientes; 39 (65\%) por A. baumannii y 21 (35\%) producidas por $P$. aeruginosa. El diagnóstico incluía neumonía $(33 \%)$, ITU (20\%), bacteriemias (15\%), infecciones del SNC (7\%), infecciones del sitio quirúrgico $(8 \%)$, peritonitis $(7 \%)$, infecciones asociadas a catéter $(7 \%)$ y otitis media $(2 \%)$. De ellas, $56(93 \%)$ se habían tratado previamente con otros antimicrobianos. Evolucionaron favorablemente 35 pacientes $(58 \%)$, falleciendo 22 (37\%). La dosis diaria media de colistín fue $152,8 \pm 62,8 \mathrm{mg}(60-300 \mathrm{mg})$ y la duración media de la terapia fueron $14 \pm 5,1$ días. El tratamiento con colistín fracasó en 15 de 20 neumonías ocasionadas por ambos microorganismos, pero este resultado no fue diferenciado por agente bacteriano. El resultado se consideró bueno para otras infecciones con 4/5 infecciones 
del SNC (meningitis, ventriculitis) y 7/9 infecciones del torrente circulatorio con evolución favorable. Un $27 \%$ de los pacientes (11/41) con función renal basal normal mostró deterioro de la creatininemia durante el tratamiento. De 19 pacientes con creatininemia alterada al inicio del tratamiento, 58\% (n 11) tuvo un deterioro adicional de la función renal. El tratamiento no fue descontinuado por nefrotoxicidad. No se observó neurotoxicidad clínica, pero no se realizaron mediciones objetivas de función neurológica ${ }^{93}$.

Este estudio sugiere que colistín es una opción eficaz para infecciones multi-resistentes, como meningitis y bacteriemia, pero tal vez no para neumonía. Si bien esto contradice estudios previos, se desconoce si este resultado insuficiente se debe a un patógeno específico ( $P$. aeruginosa o A. baumannii) puesto que las fallas de tratamiento no se estratificaron por etiología $a^{93}$.

Beltrán y $\operatorname{cols}^{27}$ reportan una serie de 14 pacientes, de los cuales 12 tenían infección por ABPDR, tratados con colistín en dos centros chilenos. Once pacientes tuvieron neumonía, 1 ITU y 2 ambas infecciones. La dosis estándar de 100 mg cada 8 horas se dio a la mitad de los pacientes. En promedio los pacientes se trataron por 18,4 días, (mediana 17 días). La mitad de los pacientes mejoró clínicamente y erradicó el microorganismo. Otro $14,3 \%$ mejoró sin erradicación bacteriológica. Un 35,7\% presentó deterioro reversible de la función renal. Fallecieron 4 pacientes $(28,6 \%)$. Estos resultados confirman lo reportado en estudios extranjeros.

Berlana ${ }^{94}$ comunicó una serie reciente de 80 pacientes, 50 de los cuales tenían infecciones por AB-PR y 19 por AB-MR. Dos tercios de los pacientes tenían aislado de $A$. baumannii desde vía aérea. Para infecciones por $A$. baumannii se reportan 60 cursos de tratamientos inhalatorios con colistín, 12 endovenosos y 2 intratecales. El $73 \%$ de los pacientes recibió concomitantemente otro agente antimicrobiano endovenoso, el más comúnmente asociado fue un carbapenémico $(35 \%)$ La duración media del tratamiento fueron $12 \pm 8$ días. Un $98 \%$ de los pacientes erradicó el agente bacteriano. La mortalidad fue de $18 \%$.

Recientemente Petrosillo y cols ${ }^{95}$ presentaron una serie de 14 pacientes de unidad critica, infectados con AB-PR (10 varones, edad promedio 49 años). Todos fueron ventilados mecánicamente y desarrollaron NAV, en dos hubo además bacteriemia y en otros dos infección de herida operatoria. Todos recibieron colistín más rifampicina por un tiempo promedio de 12 días (mediana 12, rango 2 - 24 días). Cinco de diez pacientes con cepas susceptibles a ampicilina/ sulbactam recibieron además tal antimicrobiano. Sólo un paciente experimentó deterioro de función renal y no requirió medidas de reemplazo. La mitad de los pacientes (7) falleció, 5 de ellos por AB-PR y los otros por diferente sobre infección. La cura microbiológica se obtuvo en 9 pacientes $(64 \%)$. Se concluyó que la combinación de colistín más rifampicina pudiera ser una alternativa terapéutica a considerar en infecciones por AB-PR.

Se ha publicado dos reportes de caso de terapia exitosa de meningitis ocasionada por $A$. baumannii con colistín endovenoso ${ }^{96,97}$. El primer paciente fue sometido a una craneotomia por un meningioma recidivado. En el vigésimo día postoperatorio, el paciente experimentó compromiso de conciencia y fiebre ${ }^{96}$. Se obtuvo aislado de A. baumannii PR, sólo susceptible a colistín (CIM $1 \mathrm{mg} / \mathrm{dl}$ ) en LCR. El paciente se trató por 15 días con colistín endovenoso. Luego del cuarto día de tratamiento el cultivo de LCR se negativizó y el examen citoquímico de LCR se normalizó a los diez días de terapia. La creatininemia y el nitrógeno ureico permanecieron normales durante el tratamiento. Tras cuatro días de terapia se midieron concentraciones de colistín en suero y LCR una hora luego de su administración. La concentración de colistín en LCR fue $1,25 \mathrm{mg} / \mathrm{l}$ y la concentración sérica concomitante fue $5 \mathrm{mg} / \mathrm{l}$.

En otro caso, se trató a un adolescente con TEC grave, asociado a fractura occipital, hematomas subdural y frontales bilaterales, hidrocéfalo y severa hipertensión endocraneana ${ }^{97}$. En el cuadragésimo día postoperatorio, se realizó un shunt ventrículo peritoneal. Dos días después el paciente inició fiebre, cefalea, náuseas, vómitos, dolor abdominal y somnolencia. Se aisló $A$. baumannii PR en LCR, sólo susceptible a colistín (CIM 0,3125 mg/dl). El paciente se trató con 5 $\mathrm{mg} / \mathrm{kg} /$ día de colistín. Luego de cinco días el LCR se hizo estéril. Los parámetros farmacocinéticos y farmacodinámicos se determinaron al cuarto día de tratamiento. Las concentraciones de colistín en el LCR permanecieron iguales o mayores que la CIM de las cepas durante todo el periodo de dosificación. El paciente recibió colistín endovenoso durante 30 días.

Estos dos reportes de casos sugieren que colistín endovenoso sería una posible opción para la meningitis causada por cepas de $A$. baumannii susceptibles.

Diversos estudios reportan series de pacientes con infecciones por otros bacilos gramnegativos multiresistentes tratados con colistín ${ }^{98,99}$ o con polimixina $\mathrm{B}^{100-103}$, u otras combinaciones de 
antimicrobianos dentro de los cuales se incluyen casos de AB-MR o AB-PR. Estos reportes también se resumen en la Tabla 4.

\section{Sulbactam}

Sulbactam, un inhibidor de $\beta$-lactamasas, sería otra opción para el manejo de infecciones por AB-MR. Sulbactam ha mostrado tener además de su actividad como inhibidor de $\beta$-lactamasas, cierta actividad antimicrobiana intrínseca. Los inhibidores de $\beta$-lactamasas son utilizados para proteger antimicrobianos $\beta$-lactámicos de la hidrólisis de enzimas bacterianas. Actualmente existen tres tipos de inhibidores: ácido clavulánico, sulbactam y tazobactam. Sulbactam tiene actividad contra Neisseria gonorrhoeae, Neisseria meningitidis, Burkholderia cepacia y Acinetobacter sp. Los otros inhibidores de $\beta$-lactamasas tienen menor actividad que sulbactam frente a Acinetobacter $\mathrm{sp}^{105}$. La actividad antibacteriana de sulbactam es consecuencia de su unión irreversible con PBP 2.

En Chile, sulbactam se expende comercialmente en combinación con ampicilina (Unasyn ${ }^{\circledR}$ ), amoxicilina (Sulbamox ${ }^{\circledR}$ ) o cefoperazona (Sulperazon $\left.{ }^{\circledR}\right)$. Unasyn ${ }^{\circledR}$ está formulado en combinación fija 2:1 de ampicilina/ sulbactam dosificándose cada seis horas en pacientes con función renal normal. Se distribuye en forma amplia en el organismo, pero penetra en forma pobre al LCR con meninge no inflamada. Las concentraciones de sulbactam en LCR aumentan cuando la meninge está inflamada. El fármaco se excreta sin modificaciones a través de la orina. La vida media del sulbactam es aproximadamente una hora ${ }^{106}$. Valcke y cols ${ }^{107}$ comunicaron una concentración media de 26,6 \pm $7,6 \mu \mathrm{g} / \mathrm{ml}$ de sulbactam luego de una hora de terminada la infusión, en fluido alveolar de pacientes con infección del tracto respiratorio.

En general, ampicilina/sulbactam es bien tolerada, siendo sus efectos adversos más frecuentes diarrea y dolor en el sitio de infusión. Dado que sulbactam tiene actividad in vitro contra Acinetobacter sp, se ha utilizado en el manejo de infecciones por $\mathrm{AB}-\mathrm{MR}$.

Hasta enero de 2005 no existen estudios clínicos aleatorios publicados que evalúen la eficacia de sulbactam en el tratamiento de infecciones nosocomiales por Acinetobacter. Los datos disponibles en relación a sus resultados clínicos provienen de unos pocos reportes de casos y estudios no controlados. El primer reporte publicado del uso de sulbactam data de $1993^{108}$. En un reporte de un brote neoyorquino de A. calcoace- ticus biotipo anitratus resistente a imipenem, 10 pacientes se trataron con ampicilina/sulbactam. Seis de ellos tenían neumonía, 3 traqueo bronquitis y uno bacteriemia. Solamente 5 tratados más de tres días presentaron mejoría clínica o mostraron erradicación del agente resistente desde el sitio de infección. Los exámenes de susceptibilidad in vitro mostraron que ampicilina/sulbactam tenía la mejor actividad, mientras que amoxicilina/ clavulánico y piperacilina/tazonam sólo tenían actividad moderada. Todos los aislados eran susceptibles a polimixina. Cuando los inhibidores de $\beta$-lactamasas fueron testeados individualmente, sulbactam mostró tener actividad antibacteriana versus clavulanato o tazobactam/piperacilina.

En una serie de casos retrospectiva se evaluó la evolución de pacientes politraumatizados críticos con NAV asociada a A. baumannii tratados con ampicilina/sulbactam o imipenem/cilastatina $^{106}$. Posterior a la realización de lavado broncoalveolar se inicio antibioterapia empírica. Cuando A. baumannii era resistente o de susceptibilidad intermedia a imipenem se utilizó ampicilina/ sulbactam. Imipenem se utilizó cuando las cepas eran susceptibles a éste; sin embargo, la elección de la terapia definitiva era discrecional del médico tratante. También fue a discreción del tratante el uso de terapia combinada; sin embargo, esto fue excepcional. Se pesquisaron 77 episodios de NAV por Acinetobacter. Las características basales de los pacientes no fueron significativamente diferentes. El éxito en el tratamiento de la NAV fue similar en ambos grupos, al igual que la morbilidad, pero la estadía hospitalaria y de UCI fue más larga en el grupo tratado con ampicilina/ sulbactam. La mortalidad global no fue significativamente distinta en ambos grupos, pero el uso de terapia combinada fue más común en el grupo que recibió ampicilina/sulbactam $(\mathrm{p}=0,01)$. Los resultados clínicos entre ambos grupos no fueron diferentes, empero este estudio se ve limitado en la relevancia de sus conclusiones por el escaso número de pacientes que recibió ampicilina/sulbactam y por el efecto confundente de la terapia combinada ${ }^{109}$. Se demostraría entonces que ampicilina/sulbactam es una opción de manejo de la NAV por A. baumannii resistente a imipenem, pero que tal alternativa requeriría un uso combinado con este último antimicrobiano.

Otro grupo de investigadores reportó su experiencia en el tratamiento de 40 pacientes con infecciones nosocomiales debidas a AB-MR con ampicilina/sulbactam entre mayo 1996 y enero $1998^{110}$. Todas las cepas fueron resistentes a penicilinas, cefalosporinas, aminoglucósidos, fluoroquinolonas, imipenem y aztreonam, pero 
fueron susceptibles a colistín. Las infecciones incluían bacteriemia primaria $(32,5 \%)$, neumonía (30\%), ITU (15\%), peritonitis $(7,5 \%)$, infecciones del sitio operatorio $(7,5 \%)$, meningitis $(5 \%)$ y sinusitis $(2,5 \%)$. Veintisiete pacientes $(67,5 \%)$ se consideraron curados o mejorados por su tratante luego de la terapia con ampicilina/ sulbactam, $7(17,5 \%)$ se consideraron fracaso de tratamiento y $6(15 \%)$ de resultado incierto. No se reportaron efectos adversos. Los pacientes con evolución favorable tenían un índice APACHE II mejor versus aquellos donde la terapia fracasó (media \pm DS 12,4 \pm 7, 1 versus 19,6 $\pm 4,7, \mathrm{p}=0,0015)$.

Cisneros y cols ${ }^{13}$ comunicaron la evaluación de resultados relativos a 79 pacientes con bacteriemia por $A$. baumannii. Veintiún paciente fueron tratados inapropiadamente según los resultados de la susceptibilidad in vitro. De los restantes pacientes, 8 fueron tratados con ampicilina/ sulbactam y 42 con imipenem, con tasa de respuesta de 83 y $88 \%$ respectivamente. Otros 8 pacientes fueron tratados con ceftazidima $(n=7)$ o netilmicina $(\mathrm{n}=1)$. El $99 \%$ de los pacientes tenía aislados resistentes a imipenem, mientras que sólo $7 \%$ era resistente a ampicilina/sulbactam.

Otro estudio retrospectivo de pacientes con bacteriemia por A. baumannii tratados al menos por tres días con ampicilina/sulbactam $(n=30)$ o imipenem $(n=18)$ ha sido reportado; en ambos grupos el tracto respiratorio fue el sitio de infección más común ${ }^{111}$. Al 44\% de los pacientes del grupo de imipenem y a $37 \%$ del grupo de sulbactam/ampicilina se le asoció un aminoglucósido. La erradicación de la bacteriemia se consiguió en $97 \%$ de los pacientes con ampicilina/ sulbactam y en $100 \%$ de los tratados con imipenem. La estadía en UCI fue significativamente más prolongada en el grupo de imipenem con terapia combinada versus el tratado con monoterapia, 57 versus 33 días respectivamente $(\mathrm{p}=0,03)$. No hubo diferencia de resultados clínicos entre los grupos tratados con la combinación de ampicilina/sulbactam y los tratados con monoterapia. Este estudio demostraría la utilidad potencial de ampicilina/sulbactam en pacientes con bacteriemia por A. baumannii.

En 2003, investigadores israelitas reportaron su experiencia con ampicilina/sulbactam en el manejo de AB-MR comparándolo con el estándar de cuidados en 94 pacientes con bacteriemia ${ }^{48}$. La mayoría de los pacientes fueron tratados con ampicilina/sulbactam. Comparados con el grupo estándar, el grupo de ampicilina/sulbactam no mostró diferencias significativas en la mortalidad global (40,5 versus 42,4\%, respectivamente). En los pacientes más gravemente enfermos, ampicilina/sulbactam se asoció con mortalidad significativamente menor.

Horianopoulou y cols utilizaron ampicilina/ sulbactam parenteral e inhalatoria en una serie de 20 pacientes con NAV por AB-MR ${ }^{112}$. Se asignó en forma aleatoria la mitad de los pacientes para recibir terapia endovenosa con ampicilina/sulbactam, asociada o no a su administración inhalatoria. La dosis parenteral fue de $3 \mathrm{gr}$ cada 8 horas y la dosis nebulizada fue de 3 gr en $3 \mathrm{ml}$ de agua estéril cada $8 \mathrm{hrs}$. Se tomaron estudios cuantitativos de secreciones bronquiales diariamente hasta el día séptimo de terapia. En el grupo con terapia inhalatoria el conteo de cepas viables de $A$. baumannii se redujo de un basal de $10^{7}-10^{8} \mathrm{UFC} / \mathrm{ml}$ a menos de $10^{2} \mathrm{UFC} / \mathrm{ml}$ al segundo o tercer día de tratamiento. En contraste, en el grupo con terapia parenteral exclusiva no hubo reducción en el conteo bacteriano a los 2-3 días y sólo se constató reducción a $10^{5}-10^{6} \mathrm{UFC} / \mathrm{ml}$ al séptimo día de tratamiento. Estos hallazgos sugerirían que la adicción de ampicilina/sulbactam nebulizada a la terapia antibacteriana endovenosa estándar es una medida eficaz para reducir la colonización del tracto respiratorio por $\mathrm{AB}-\mathrm{MR}$ en UCI, disminuyendo el riesgo de NAV por tal agente.

Otros estudio pequeño ${ }^{113}$ reportó el tratamiento de meningitis ocasionada por AB-MR con ampicilina/sulbactam. Siete de 8 pacientes recibieron ampicilina/sulbactam. Todas las cepas identificadas en estos pacientes eran resistentes a ciprofloxacina, gentamicina y ceftazidima; sólo una era susceptible a imipenem. No se menciona si se estudió susceptibilidad para colistín. La mayoría de los pacientes obtuvo mejoría.

Cawley y cols ${ }^{114}$ comunicaron el caso de un pacientes de 52 años con meningitis causada por A. baumannii. La cepa era resistente a amikacina e imipenem. El paciente recibió ampicilina/ sulbactam $4 \mathrm{gr} / 2 \mathrm{gr}$ cada seis horas por tres días y luego se cambió a 2gr/1gr cada tres horas. Luego de 35 días de terapia, la infección se resolvió sin efectos adversos.

Según Bello y cols ${ }^{115}$, la susceptibilidad de 280 cepas nacionales de A. baumannii para ampicilina/ sulbactam ha caído de $100 \%$ en el periodo 199092 a sólo 43,7\% en los años 1997-98. Atribuyen ese hecho al excesivo uso de esta combinación en pacientes con infecciones o colonizaciones por A. baumannii.

Sulperazon ${ }^{\circledR}$ es cefoperazona/sulbactam mezcla que se comercializa en Europa, Asia y Latinoamérica, pero no esta licenciada por la FDA en E.U.A. Está formulada en proporciones 
fijas de 2:1 y 1:1 para cefoperazona y sulbactam respectivamente. En base a cefoperazona se dosifica para adultos 2 a 4 gr cada 12 horas ${ }^{116}$. En Chile sólo se dispone de la formulación 2:1. Esta combinación es más resistente al ataque de las $\beta$ lactamasas de clase A de Ambler pero se mantiene vulnerable a cepas productoras de AmpC clase D Ambler- ${ }^{117}$.

Existe abundante información de estudios in vitro que sugiere mejor actividad de cefoperazona/ sulbactam que cefoperazona sola frente a $A$. baumannii $^{118}$. Sin embargo, los criterios para definir cepas susceptibles son disímiles, dado que no existen concentraciones estándares del NCCLS para test de dilución en agar o discos de difusión para la mezcla. Muchos estudios consideran sólo la CIM para cefoperazona, algunos usan proporciones 2:1 y otros no mencionan la concentración de sulbactam utilizada ${ }^{118}$. La mezcla parece ser más activa in vitro que muchos otros $\beta$-lactámicos, con la salvedad de los carbapenémicos ${ }^{119}$.

Para esta revisión se encontró sólo un estudio que evalúa la eficacia clínica de cefoperazona/ sulbactam en infecciones por AB-MR ${ }^{112}$. De 19 pacientes, en $79 \%(n=15)$ se obtuvo resolución clínica de la infección a los 10 días de terapia con la combinación. Sin embargo, en 7 pacientes (37\%) se adicionó rifampicina 300-600 mg/día. Todas las cepas, salvo una, eran susceptibles a cefoperazona/sulbactam y sólo una resistente a imipenem. La dosis media diaria de cefoperazona/ sulbactam utilizada fue de $3 \mathrm{gr} / 1,5 \mathrm{gr}$ respectivamente. Hubo fracaso de tratamiento en $10,5 \%$ de los casos $(\mathrm{n}=2)$ y falleció un número similar de pacientes. Los autores plantean que cefoperazona/ sulbactam sería una apropiada opción terapéutica previa al uso de carbapenémicos frente a infecciones graves causadas por A. baumannii.

Dada la escasa y disímil información sobre eficacia clínica de cefoperazona/sulbactam en infecciones por AB-MR, cuesta formarse una idea clara de su real papel en su manejo, aun cuando debe ser la asociación de $\beta$-lactámico/ inhibidor de $\beta$-lactamasa más usada para infecciones nosocomiales producidas por A. baumannii en nuestro país, dependiendo de los diferentes centros hospitalarios.

Sulbamox ${ }^{\circledR}$ es una combinación 2:1 de amoxicilina/sulbactam desarrollada en Argentina y que se comercializa fundamentalmente en Latinoamérica $^{121}$. No existen artículos relativos a eficacia in vitro o in vivo de esta combinación frente a infecciones por A. baumannii, ni tampoco estudios clínicos pertinentes publicados. Por tanto, hasta que surja información al respecto, debiera desaconsejarse su uso para infecciones por AB-MR o AB-PR.

Otra forma de uso de sulbactam frente a ABMR es como agente individual en asociación con otros agentes antimicrobianos. Recientemente Lee y cols ${ }^{24}$ reportaron el uso combinado de sulbactam más imipenem o meropenem en un estudio retrospectivo de 89 pacientes. Cincuenta y nueve fueron tratados con un carbapenémico más sulbactam en proporción 1:1 y 30 con una asociación de cefalosporina de $2^{\mathrm{a}}$ ó $3^{\mathrm{a}}$ generación, penicilina anti-pseudomonas o fluoroquinolona más amikacina. No hubo diferencias significativas en las ramas del estudio respecto de cura o mejoría clínica ni sobrevida (59 vs $60 \%$ y 59 vs $57 \%$ respectivamente). En la erradicación bacteriológica el grupo de carbapenémico/sulbactam alcanzó 36 versus 47\% del comparador. Se concluyó que la combinación carbapenémico/sulbactam no mejoraría el éxito clínico en infecciones por AB-PR.

\section{Tetraciclinas}

Las tetraciclinas también se han evaluado para el tratamiento de AB-MR. Wood y cols ${ }^{122}$ reportaron una pequeña serie de casos de NAV por $A$. baumannii tratados con doxiciclina y minociclina. Se diagnosticó NAV ante síntomas y signos clínicos de neumonía (por ejemplo: fiebre, leucocitosis, esputo purulento, hallazgos radiológicos torácicos, etc.) y cultivo de LBA con más de $10^{5}$ UFC. Cinco pacientes tenían cepas resistentes a todos los antimicrobianos salvo minociclina y doxiciclina. Seis pacientes se consideraron con mejoría clínica después del tratamiento. En cuatro pacientes se repitió el cultivo de LBA no evidenciando crecimiento de A. baumannii. Los investigadores concluyeron que estas tetraciclinas podrían ser eficaces para tratar NAV por AB-PR.

La tigeciclina, en rigor una glicilciclina, ha mostrado una estupenda actividad in vitro frente a A. baumannii. En 155 cepas de distintas colecciones internacionales de seguimiento de resistencia, tigeciclina fue activa en $98,7 \%(\mathrm{CIM} \geq 2$ $\mu \mathrm{g} / \mathrm{ml})^{123}$. En cepas clínicas de AB-MR, de las cuales $72 \%$ eran resistentes a imipenem (AB$\mathrm{PR}$ ), todas fueron susceptibles a tigeciclina (CIM $\geq 16 \mu \mathrm{g} / \mathrm{ml}$, según puntos de corte NCCLS para minociclina); sin embargo, en el estudio de curvas de muerte en el tiempo la tigeciclina mostró ser sólo bacteriostática ${ }^{124}$.

El uso de tetraciclinas y sus derivados para NAV u otras infecciones por A. baumannii requiere mayor información para definir un rol definitivo en clínica. 


\section{Manejo práctico de $A B-P R$}

El aislado de $A$. baumannii multi-resistente es un problema que desafortunadamente se hará cada vez más frecuente en la medida que no controlemos los factores de riesgo asociados a su emergencia. La restricción en el uso de cefalosporinas de amplio espectro y carbapenémicos es una probable herramienta de intervención al respecto ${ }^{14,40,42,45}$. Por lo demás, siempre que se aísle $A$. baumannii debemos evaluar si se trata de una verdadera infección o de una simple colonización. Esta premisa es aún más importante en el caso de cepas pan-resistentes. De todas formas, si decidimos que debemos tratarlo y no se dispone de algún antibacteriano según el antibiograma, ni siquiera colistín, pudiéramos tener algunas otras opciones.

Según Garnacho ${ }^{125}$ en primer lugar, deberíamos determinar la CIM para imipenem. Si la CIM está en niveles de resistencia pero no es muy elevada (16 ó $32 \mu \mathrm{g} / \mathrm{ml}$ ), es muy posible que según los datos de modelos experimentales, la infección se erradique con dosis elevadas de imipenem $^{77}$. Si por el contrario la CIM es muy elevada (216 ó $532 \mu \mathrm{g} / \mathrm{ml}$ ), se pueden intentar tratamientos sinérgicos combinando imipenem más colistín, imipenem más rifampicina, colistín más rifampicina e incluso los tres antibacterianos $^{78,126}$. Hay que decir, que en un modelo in vitro se ha demostrado un efecto sinérgico de la combinación de estos tres antimicrobianos sobre cepas de A. baumannii $\mathrm{MR}^{127}$. Se especula que un posible mecanismo de esta sinergia es la permeabilización de la membrana externa por acción de colistín, lo que permitiría la penetración y actuación de los otros dos antimicrobianos. Esto sería válido si el mecanismo de resistencia a imipenem es por alteraciones de las porinas y no por $\beta$-lactamasas.

El conocimiento de los diversos aspectos epidemiológicos, clínicos, microbiológicos y de los antimicrobianos reseñados en el presente artículo puede ayudarnos a un correcto diagnóstico y tratamiento de las infecciones causadas por AB-PR.

\section{Resumen}

En las ultimas dos décadas Acinetobacter baumannii ha emergido como un patógeno nosocomial de la mayor relevancia mundial. A baumannii puede ser agente causal de infecciones como neumonía, bacteriemia, meningitis, infecciones del tracto urinario y de partes blandas, asociándose a alta mortalidad. Diversas comunicaciones nacionales y extranjeras revelan el aislamiento de cepas resistentes a casi todos los agentes antimicrobianos comercialmente disponibles, por lo que las opciones terapéuticas se han limitado drásticamente. Esto plantea la necesidad de desarrollar nuevos agentes antibacterianos y resucitar ciertos compuestos abandonados, como las polimixinas, para optimizar la terapéutica de este microorganismo con múltiple resistencia. Con el objeto de revisar y evaluar los datos sobre el manejo de infecciones multirresistentes por A baumannii, se realizó una revisión sistemática de la literatura médica que incluyó MEDLINE y LILACS, identificando y categorizando la relevancia clínica de las fuentes recolectadas a la fecha de esta investigación. Se repasan aspectos epidemiológicos clínicamente relevantes, datos microbiológicos y estudios clínicos realizados con infecciones por $A$ baumannii pan resistente (AB-PDR) o multirresistente (AB-MDR). La respuesta apropiada al manejo de infecciones por AB-PDR es compleja, su erradicación requiere de adherencia a prácticas adecuadas de control de infecciones y del uso prudente de antimicrobianos, además del empleo de antibioterapia eficaz. Potenciales opciones de terapia serian la colistina, asociaciones de betalactámicos con sulbactam y tetraciclinas pero no existen estudios controlados y aleatorios al respecto.

\section{Referencias}

1.- Richards M J, Edwards J R, Culver D H, Gaynes R P. Nosocomial infections in medical intensive care units in the United States. National Nosocomial Infections Surveillance System. Crit Care Med 1999; 27: 88792.

2.- Fluit A C, Jones M E, Schmitz F J, Acar J, Gupta R, Verhoef J. Antimicrobial susceptibility and frequency of occurrence of clinical blood isolates in Europe from the SENTRY antimicrobial surveillance program, 1997 and 1998. Clin Infect Dis 2000; 30: 454-60.

3.- Gales A C, Jones R N, Forward K R, Linares J, Sader HS, Verhoef J. Emerging importance of multidrugresistant Acinetobacter species and Stenotrophomonas maltophilia as pathogens in seriously ill patients: geographic patterns, epidemiological features, and trends in the SENTRY. Antimicrobial Surveillance Program (1997-1999). Clin Infect Dis 2001; 32 (Suppl 2): S104 -S13.

4.- Brenner P, Otaíza F, Bustamante R. Nosocomial infections outbreaks in Chile 1985-2002. Am J Infect Control 2004; 32 (3): E49.

5.- Ministerio de Salud. República de Chile. Departamento de Programación. Recomendaciones para el manejo epidemiológico de infecciones intrahospitalarias por Acinetobacter calcoaceticus subespecie antitratus. Circular No 77. 13 de octubre de 1989.

6.- Otaíza F, Brenner P, Pohlenz M, Valenzuela M. Informe de vigilancia epidemiológica de las infecciones intrahospitalarias. Infecciones Intrahospitalarias 1999-2000. MINSAL. Departamento de Calidad de Prestadores. División de Planificación y Presupuesto.

7.- MINSAL. Informe de vigilancia epidemiológica de las infecciones intrahospitalarias. Infecciones 
Intrahospitalarias 2001. Departamento de Calidad de Prestadores. División de Planificación y Presupuesto.

8.- Brenner P, Pohlenz M, Otaíza F. Informe de vigilancia epidemiológica de las infecciones intrahospitalarias. Infecciones Intrahospitalarias 2002. MINSAL. Departamento de Calidad de Prestadores. División de Planificación y Presupuesto.

9.- Otaíza F, Brenner P, Pohlenz M. Informe de vigilancia epidemiológica de las infecciones intrahospitalarias. Infecciones Intrahospitalarias 2003. MINSAL. Departamento de Calidad de Prestadores. División de Planificación y Presupuesto.

10.- Allen D M, Hartman B J. Acinetobacter Species. In: Mandell GL, Bennett JE, Dolin R, eds. Mandell, Douglas and Bennett's Principles and Practice of Infectious Diseases. 6th ed. Elsevier Churchill Livingstone, Philadelphia. 2005: 2632-5.

11.- Beck-Sague C M, Jarvis W R, Brook J H, Culver D H, Potts A, Gay E, et al. Epidemic bacteremia due to Acinetobacter baumannii in five intensive care units. Am J Epidemiol 1990; 132: 723-33.

12.- Seifert H, Strate A, Pulverer G. Nosocomial bacteremia due to Acinetobacter baumannii. Clinical features, epidemiology, and predictors of mortality. Medicine (Baltimore) 1995; 74: 340-9.

13.- Cisneros J M, Reyes M J, Pachón J, Becerril B, Caballero F J, García-Garmendia JL, et al. Bacteremia due to Acinetobacter baumannii: epidemiology, clinical findings, and prognostic features. Clin Infect Dis 1996; 22: 1026-32.

14.- García Garmendia J L, Ortiz Leyba C, Garnacho Montero J, Jiménez Jiménez F J, Pérez Paredes C, Barrero Almodóvar A E, et al. Risk factors for Acinetobacter baumannii nosocomial bacteremia in critically ill patients: a cohort study. Clin Infect Dis 2001; 33: 939-46.

15.- Fagon J Y, Chastre J, Domart Y, Trouillet J L, Gibert C. Mortality due to ventilator -associated pneumonia or colonization with Pseudomonas or Acinetobacter species: assessment by quantitative culture of samples obtained by a protected specimen brush. Clin Infect Dis 1996; 23: 538 - 42.

16.- Bergogne-Berezin E, Towner K J. Acinetobacter spp. as nosocomial pathogens: microbiological, clinical, and epidemiological features. Clin Microbiol Rev 1996; 9: 148-65

17.- Go E S, Urban C, Burns J, Kreiswirth B, Eisner W, Mariano N, et al. Clinical and molecular epidemiology of Acinetobacter infections sensitive only to polymyxin B and sulbactam. Lancet 1994; 344: 1329. 32.

18.- Mahgoub S, Ahmed J, Glatt A E. Completely resistant Acinetobacter baumannii strains. Infect Control Hosp Epidemiol 2002; 23: 477-9.

19.- Simor A E, Lee M, Vearncombe M, Jones-Paul L, Barry C, Gómez M, et al. An outbreak due to multiresistant Acinetobacter baumannii in a burn unit: risk factors for acquisition and management. Infect Control Hosp Epidemiol 2002; 23: 261-7.

20.- Wong T H, Tan B H, Ling M L, Song C. Multiresistant Acinetobacter baumannii on a burns unit clinical risk factors and prognosis. Burns 2002; 28: 349-57.

21.- Abbo A, Navon-Venezia S, Hammer-Muntz O, Krichali T, Siegman-Igra Y, Carmeli Y. Multidrugresistant Acinetobacter baumannii. Emerg Infect Dis 2005; 11: 22-9.
22.- Jain R, Danziger L H. Multidrug-resistant Acinetobacter infections: an emerging challenge to clinicians. Ann Pharmacother 2004; 38: 1449-59.

23.- Hsueh P R, Teng L J, Chen C Y, Chen W H, Yu C J, Ho S W, et al. Pandrug-resistant Acinetobacter baumannii causing nosocomial infections in a university hospital, Taiwan. Emerg Infect Dis 2002; 8: $827-32$.

24.- Lee C M, Lim H K, Liu C P, Tseng H K. Treatment of pan-drug resistant Acinetobacter baumannii. Scand J Infect Dis 2005; 37: 195-9

25.- Reis A O, Luz D A, Tognim M C, Sader H S, Gales A C. Polymyxin-resistant Acinetobacter spp. isolates: what is next? Emerg Infect Dis 2003; 9: 1025-7.

26.- Diomedi A, Herrera C, Arancibia F, Gavilán J, Soto L, Giscard A, et al. Neumonía nosocomial por Acinetobacter baumannii pandroga-resistente: primera comunicación nacional. XIX Congreso Chileno de Infectología, Santiago 2002; Resumen PO55.

27.- Beltrán C, Diomedi A, Cerda S, Bugueño R, Macias F, Cornejos E, et al. Eficacia y seguridad de colistín en dos hospitales chilenos. XXI Congreso Chileno de Infectología, Viña del Mar 2004; Resumen CO70.

28.- Gerner-Smidt P. Acinetobacter: epidemiological and taxonomic aspects. APMIS Suppl 1994; 47: 1-41.

29.- Bouvet P J M, Grimont P A D. Taxonomy of the genus Acinetobacter with the recognition of Acinetobacter baumannii sp nov, Acinetobacter haemolyticus sp. no., Acinetobacter johnsonii sp. nov., and Acinetobacter junii sp. nov. and embedded descriptions of Acinetobacter calcoaceticus and Acinetobacter lwoffi. Int J Syst Bacteriol 1986; 36: 228-40.

30.- Gervich D H, Grout C S. An outbreak of nosocomial Acinetobacter infections from humidifiers. Am J Infect Control 1985; 13: 210 -5.

31.- Cefai C, Richards J, Gould F K, McPeake P. An outbreak of Acinetobacter respiratory tract infection resulting from incomplete disinfection of ventilatory equipment. J Hosp Infect 1990; 15: 177-82.

32.- Adams B G, Marrie T J. Hand carriage of aerobic gram-negative rods by health care personnel. J Hyg (Lond) 1982; 89: 23-31.

33.- Guenthner S H, Hendley J O, Wenzel R P. Gramnegative bacilli as non-transient flora on the hands of hospital personnel. J Clin Microbiol 1987; 25: 488-90.

34.- Sherertz R J, Sullivan M L. An outbreak of infections with Acinetobacter calcoaceticus in burn patients: contamination of patients' mattresses. J Infect Dis 1985; 151: 252-8.

35.- Weernink A, Severin W P, Tjernberg I, Dijkshoorn L. Pillows, an unexpected source of Acinetobacter. J Hosp Infect 1995; 29: 189-99.

36.- Hirai Y. Survival of bacteria under dry conditions; from a viewpoint of nosocomial infection. J Hosp Infect 1991; 19: 191-200.

37.- Getchell-White S I, Donowitz L G, Groschel D H. The inanimate environment of an intensive care unit as a potential source of nosocomial bacteria: evidence for long survival of Acinetobacter calcoaceticus. Infect Control Hosp Epidemiol 1989; 10: 402-7.

38.- Buxton A E, Anderson R L, Werdegar D, Atlas E. Nosocomial respiratory tract infection and colonization with Acinetobacter calcoaceticus. Epidemiologic characteristics. Am J Med 1978; 65: 507-13. 
39.- Chen M Z, Hsueh P R, Lee L N, Yu C J, Yang P C, Luh K T. Severe community-acquired pneumonia due to Acinetobacter baumannii. Chest 2001; 120: 1072-7.

40.- Lortholary O, Fagon J Y, Hoi A B, Slama M A, Pierre J, Giral P, et al. Nosocomial acquisition of multiresistant Acinetobacter baumannii: risk factors and prognosis. Clin Infect Dis 1995; 20: 790-6.

41.- Wisplinghof F H, Edmond M B, Pfaller M A, Jones R N, Wenzel R P, Seifert H. Nosocomial bloodstream infections caused by Acinetobacter species in United States hospitals: clinical features, molecular epidemiology, and antimicrobial susceptibility. Clin Infect Dis 2000; 31: 690-7.

42.- Mahgoub S, Ahmed J, Glatt A E. Underlying characteristics of patients harboring highly resistant Acinetobacter baumannii. Am J Infect Control 2002; 30: 386-90.

43.- Fagon J Y, Chastre J, Domart Y, Trouillet J L, Pierre J, Darne C, et al. Nosocomial pneumonia in patients receiving continuous mechanical ventilation. Prospective analysis of 52 episodes with use of a protected specimen brush and quantitative culture techniques. Am Rev Respir Dis 1989; 139: 877-84.

44.- Husni R N, Goldstein L S, Arroliga A C, Hall G S, Fatica C, Stoller J K, et al. Risk factors for an outbreak of multidrug-resistant Acinetobacter nosocomial pneumonia among intubated patients. Chest 1999; 115: 1378-82.

45.- Mulin B, Talon D, Viel J F, Vincent C, Leprat R, Thouverez M, et al. Risk factors for nosocomial colonization with multiresistant Acinetobacter baumannii. Eur J Clin Microbiol Infect Dis 1995; 14: $569-76$

46.- Landman D, Quale J M, Mayorga D, Adedeji A, Vangala K, Ravishankar J, et al. Citywide clonal outbreak of multiresistant Acinetobacter baumannii and Pseudomonas aeruginosa in Brooklyn, NY: the preantibiotic era has returned. Arch Intern Med 2002; 162: 515-20.

47.- Afzal-Shah M, Liver more DM. Worldwide emergence of carbapenem-resistant Acinetobacter spp. J Antimicrob Chemother 1998; 41: 76-7.

48.- Smolyakov R, Borer A, Riesenberg K, Schlaeffer F , Alkan M, Porath A, et al. Nosocomial multi-drug resistant Acinetobacter baumannii blood-stream infection: risk factors and outcome with ampicillinsulbactam treatment. J Hosp Infect 2003; 54: 2-8.

49.- Sader H S, Fedler K A, Biedenbach D J, Fritsche T R, Jones R N. Antimicrobial susceptibility of $P$. aeruginosa and Acinetobacter spp. from bloodstream infections (BSI): Comparison of SENTRY Program results from North America, Latin America and Europe. 42nd Annual Meeting of IDSA, September 30 - October 3, 2004; Boston, USA. Abstract 365.

50.- Jones R N. The epidemiology of resistant Gram negative rods: North America. 42nd Annual Meeting of IDSA, September 30 - October 3, 2004; Boston, USA. Abstract 752.

51.- Tognim M C, Andrade S S, Silbert S, Gales A C, Jones R N, Sader H S. Resistance trends of Acinetobacter spp in Latin America and characterization of international dissemination of multi-drug resistant strains: five-year report of the SENTRY Antimicrobial Surveillance Program. Int J Infect Dis 2004; 8: 284-91.

52.- Silva J, Avello C, Matamoro F, Villagra L, Rojas E, Sandoval L. Resistencia a antimicrobianos en dife- rentes biotipos de Acinetobacter baumannii aislados en el norte de Chile. Rev Méd Chile 1999; 127: 926-34.

53.- Trucco O, Prado V, Duran C y grupo PRONARES. Red de vigilancia de resistencia antimicrobiana PRONARES: Informe primer semestre 2001. Rev Chil Infect 2002; 19: S140-S8.

54.- González P. Bacilos gram negativos no fermentadores. Tercer Curso de Microbiología Clínica, Sociedad Chilena de Infectología. Santiago, mayo de 2004. Accedido el 13/12/2004 en http://www.sochinf.cl/documentos/micro2004/9.pdf

55.- Seifert H, Baginski R, Schulze A, Pulverer G. Antimicrobial susceptibility of Acinetobacter species. Antimicrob Agents Chemother 1993; 37: 750-3

56.- Bou G, Cervero G, Domínguez M A, Quereda C, Martínez-Beltrán J. Characterization of a nosocomial outbreak caused by a multiresistant Acinetobacter baumannii strain with a carbapenem-hydrolyzing enzyme: high-level carbapenem resistance in $A$. baumannii is not due solely to the presence of betalactamases. J Clin Microbiol 2000; 38: 3299-305.

57.- Nikaido H. Bacterial resistance to antibiotics as a function of outer membrane permeability. J Antimicrob Chemother 1988; 22: 17-22.

58.- Nakae T. Outer-membrane permeability of bacteria. Crit Rev Microbiol 1986; 13: 1-62.

59.- Clark RB. Imipenem resistance among Acinetobacter baumannii: association with reduced expression of a 33-36 kDa outer membrane protein. J Antimicrob Chemother 1996; 38: 245-51.

60.- Vila J, Marco F. Lectura interpretada del antibiograma de bacilos gramnegativos no fermentadores. Enferm Infecc Microbiol Clin 2002; 20: 304-12.

61.- Vila J. Mechanisms of antimicrobial resistance in Acinetobacter baumannii. Rev Med Microbiol 1998; 9: 87-97.

62.- Nordmann P, Poirel L. Emerging carbapenemases in gram-negative aerobes. Clin Microbiol Infect 2002; 8: 321-31.

63.- Weldhagen GF, Poirel L, Nordmann P. Ambler class A extended-spectrum beta-lactamases in Pseudomonas aeruginosa: novel developments and clinical impact. Antimicrob Agents Chemother 2003; 47: 2385-92.

64.- Poirel L, Menuteau O, Agoli N, Catton C, Nordmann P. Outbreak of extended-spectrum $\beta$-lactamase VEB-1producing isolates of Acinetobacter baumannii in a French hospital. J Clin Microbiol 2003; 41: 3542-7.

65.- Jacoby G A. Extended-spectrum beta-lactamases and other enzymes providing resistance to oxyiminobeta-lactams. Infect Dis Clin North Am 1997; 11: 875-87.

66.- Vahaboglu H, Ozturk R, Aygun G, Coskunkan F, Yaman A, Kaygusuz A, et al. Widespread detection of PER-1-type extended-spectrum beta-lactamases among nosocomial Acinetobacter and Pseudomonas aeruginosa isolates in Turkey: a nationwide multicenter study. Antimicrob Agents Chemother 1997; 41: 2265-9.

67.- Vahaboglu H, Coskunkan F, Tansel O, Ozturk R, Sahin N, Koksal I, et al. Clinical importance of extended-spectrum beta-lactamase (PER-1-type)producing Acinetobacter spp and Pseudomonas aeruginosa strains. J Med Microbiol 2001; 50: 642-5.

68.- Yong D, Shin JH, Kim S, Lim Y, Yum J H, Lee K, et al. High prevalence of PER-1 extended-spectrum beta-lactamase-producing Acinetobacter spp. in 
Korea. Antimicrob Agents Chemother 2003; 47: 1749-51.

69.- Poirel L, Karim A, Mercat A, Le Thomas I, Vahaboglu H, Richard C, et al. Extended-spectrum beta-lactamase-producing strain of Acinetobacter baumannii isolated from a patient in France. J Antimicrob Chemother 1999; 43: 157-8.

70.- Carbonnea A, Naasb T, Blanckaertc K, Couzigoua C, Cattoenc $\mathrm{C}$, Chagnonc $\mathrm{J} \mathrm{L}$, et al. Investigation of a nosocomial outbreak of extended-spectrum $\beta$ lactamase VEB-1-producing isolates of Acinetobacter baumannii in a hospital setting. J Hosp Infect 2005; 60: 14-8.

71.- Oh E J, Lee S, Park Y J, Park J J, Park K, Kim S I, et al. Prevalence of metallo-betalactamase among Pseudomonas aeruginosa and Acinetobacter baumannii in a Korean University hospital and comparison of screening methods for detecting metallo-betalactamase. J Microbiol Meth 2003; 54: (41) $1-8$.

72.- Afzal-Shah M, Woodford N, Livermore D M. Characterization of OXA- 25, OXA- 26, and OXA27 , molecular class D $\beta$-lactamases associated with carbapenem resistance in clinical isolates of Acinetobacter baumannii. Antimicrob Agents Chemother 2001; 45: 583-8.

73.- Towner K J. Clinical importance and antibiotic resistance of Acinetobacter spp. Proceedings of a symposium held on 4 - 5 November 1996 at Eilat, Israel. J Med Microbiol 1997; 46: 721-46.

74.- Seward R J, T Owner KJ . Molecular epidemiology of quinolone resistance in Acinetobacter spp. Clin Microbiol Infect 1998; 4: 248-54.

75.- Wisplinghof F H, Decker M, Haefs C, Krut O, Plum G, Seifert H. Mutations in gyr A and par C associated with resistance to fluoroquinolones in epidemiologically defined clinical strains of Acinetobacter baumannii . J Antimicrob Chemother 2003; 51: $177-80$.

76.- Ruiz J. Mechanisms of resistance to quinolones: target alterations, decreased accumulation and DNA gyrase protection. J Antimicrob Chemother 2003; 51: (1) 109-17.

77.- Montero A, Ariza J, Corbella X, Doménech A, Cabellos C, Ayats J, et al. Efficacy of colistin versus beta-lactams, aminoglycosides, and rifampin as monotherapy in a mouse model of pneumonia caused by multiresistant Acinetobacter baumannii. Antimicrob Agents Chemother 2002; 46: 1946-52.

78.- Wolff M, Joly-Guillou M L, Farinotti R, Carbon C. In vivo efficacies of combinations of beta-lactams, beta-lactamase inhibitors, and rifampin against Acinetobacter baumannii in a mouse pneumonia model. Antimicrob Agents Chemother 1999; 43: 1406-11.

79.- Pachón-Ibáñez M, Jiménez-Mejías M, Pichardo C, Martín-Lozano D, Bernabeu M, Cisneros J, et al. Efficacy of imipenem, sulbactam, and rifampin, alone and in combination, in experimental pneumonia caused by multiresistant Acinetobacter baumannii. Clin Microbiol Infect 2003; 9: 398 P1624.

80.- Joly-Guillou M L, Wolff M, Farinotti R, Bryskier A, Carbon C. In vivo activity of levofloxacin alone or in combination with imipenem or amikacin in a mouse model of Acinetobacter baumannii pneumonia. J Antimicrob Chemother 2000; 46: 827-30.

81.- Rodríguez-Hernández M J, Pachón J, Pichardo C, Cuberos L, Ibáñez- Martínez J, García-Curiel A, et al. Imipenem, doxycycline and amikacina in monotherapy and in combination in Acinetobacter baumannii experimental pneumonia. J Antimicrob Chemother 2000; 45: 493 -501.

82.- Rodríguez-Hernández M J, Cuberos L, Pichardo C, Caballero F J, Moreno I, Jiménez-Mejías M E, et al. Sulbactam efficacy in experimental models caused by susceptible and intermediate Acinetobacter baumannii strains. J Antimicrob Chemother 2001; 47: 479-82.

83.- Fetiye K I, Karadenizli A, Okay E, Oz S, Budak F, Gundes S I, Vahaboglu H. Comparison in a rat thigh abscess model of imipenem, meropenem and cefoperazone-sulbactam against Acinetobacter baumannii strains in terms of bactericidal efficacy and resistance selection. Ann Clin Microbiol Antimicrob 2004; 2: 1-5.

84.- Li J, Nation R L, Milne R W, Turnidge J D, Coulthard K. Evaluation of colistin as an agent against multi-resistant Gram-negative bacteria. Intern J Antimicrob Agents 2005; 25: 11-25.

85.- Falagas M E, Kasiakou S K. Colistin: The revival of polymyxins for the management of multidrugresistant gram-negative bacterial infections. Clin Infect Dis 2005; 40: 1333-41.

86.- Horton J, Pankey G A. Polymyxin B, colistin, and sodium colistimethate. Med Clin North Am 1982; 66: $135-42$

87.- Evans M E, Feola D J, Rapp R P. Polymyxin B sulfate and colistin: old antibiotics for emerging multiresistant gram-negative bacteria. Ann Pharmacother 1999; 33: 960-7. DOI 10.1345/aph.18426

88.- Colistín. Drugdex Drug Evaluation. Micromedex® Healthcare Series 2005; 124.

89.- Katz S L, Ho S L, Coates A L. Nebulizer choice for inhaled colistin treatment in cystic fibrosis. Chest 2001; 119: 250-5.

90.- Jensen T, Pedersen SS, Garne S, Heilmann C, Hoiby N, Koch C. Colistin inhalation therapy in cystic fibrosis patients with chronic Pseudomonas aeruginosa lung infection. J Antimicrob Chemother 1987; 19: 8318.

91.- Fernández-Viladrich P, Corbella X, Corral L, Tubau F, Mateu A. Successful treatment of ventriculitis due to carbapenem-resistant Acinetobacter baumannii with intraventricular colistin sulfomethate sodium. Clin Infect Dis 1999; 28: 916-7.

92.- Garnacho-Montero J, Ortiz-Leyba C, JiménezJiménez F J, Barrero-Almodóvar A E, GarcíaGarmendia J L, Bernabeu-Wittell M, et al. Treatment of multidrug-resistant Acinetobacter baumannii ventilator-associated pneumonia (VAP) with intravenous colistin: a comparison with imipenemsusceptible V A P. Clin Infect Dis 2003; 36: 1111-8.

93.- Levin A S, Barone A A, Penco J, Santos M V, Marinho I S, Arruda E A, et al. Intravenous colistin as therapy for nosocomial infections caused by multidrug-resistant Pseudomonas aeruginosa and Acinetobacter baumannii. Clin Infect Dis 1999; 28: 1008-11.

94.- Berlana D, Llop J M, Fort E, Badia M B, Jódar R. Use of colistin in the treatment of multiple-drug resistant gram-negative infections. Am J Health-Syst Pharm 2005; 62: 39-47

95.- Petrosillo N, Chinello P, Proietti M F, Cecchini L, Masala M, Franchi C, et al. Combined colistin and rifampicin therapy for carbapenem-resistant Acinetobacter baumannii infections: clinical out- 
come and adverse events. Clin Microbiol Infect 2005; 11: $682-4$.

96.- Jiménez-Mejías M E, Becerril B, Márquez-Rivas F J, Pichardo C, Cuberos L, Pachon J. Successful treatment of multidrug-resistant Acinetobacter baumannii meningitis with intravenous colistin sulfomethate sodium. Eur J Clin Microbiol Infect Dis 2000; 19: 970-1.

97.- Jiménez-Mejías M E, Pichardo-Guerrero C, MárquezRivas F J, Martin- Lozano D, Prados T, Pachon J. Cerebrospinal fluid penetration and pharmacokinetic/ pharmacodynamic parameters of intravenously administered colistin in a case of multidrug-resistant Acinetobacter baumannii meningitis. Eur J Clin Microbiol Infect Dis 2002; 21: 212-4.

98.- Abbas M, Chowdhury M. Salvage therapy for multidrug-resistant (MDR) Gram negative infections with intravenous colistin. 42nd Annual Meeting of IDSA, September 30 - October 3, 2004; Boston, USA. Abstract 229.

99.- Michalopoulos A S, Tsiodras S, Rellos K, Mentzelopoulos $\mathrm{S}$ and Falagas ME. Colistin treatment in patients with ICU-acquired infections caused by multiresistant Gram-negative bacteria: the renaissance of and old antibiotic. Clin Microbiol Infect 2005; 11: 115-21.

100.- Kwa A L H, Choo P L, Tan A, Low J, Tan B H. Polymyxin B in the treatment of multidrug resistant Gram negative infections. $43^{\text {rd }}$ Interscience Conference on Antimicrobial Agents and Chemotherapy. Chicago, USA. September 14-17, 2003. Abstract K-701.

101.- Lale A, Kaur G, Chow C, Singh K. Completely resistant Acinetobacter baumannii infection: to treat or not to treat. 42nd Annual Meeting of IDSA, September 30 - October 3, 2004; Boston, USA. Abstract 226.

102.- Tsveniashvili L, Leviton I. Parenteral polymyxin B for treatment of infections due to resistant Gramnegative organisms. 42nd Annual Meeting of IDSA, September 30 - October 3, 2004; Boston, USA. Abstract 230

103.- Sharma S, Kopec R, Dizon R, Pastewski A, Henry M, Ghitan $M$ et al. Return of polymyxin B- Does it work? 42nd Annual Meeting of IDSA, September 30 - October 3, 2004; Boston, USA. Abstract 204.

104.- Saballs M, Pujol M, Peña C, Tubau F, Domínguez M $\mathrm{A}$, Ariza $\mathrm{J}$ et al. Imipenem-rifampicin combination in the treatment of carbapenem-resistant Acinetobacter baumannii infections. 43rd Interscience Conference on Antimicrobial Agents and Chemotherapy. Chicago, USA. September 14-17, 2003. Abstract K-703.

105.- Urban C, Go E, Mariano N, Rahal J J. Interaction of sulbactam, clavulanic acid and tazobactam with penicillin-binding proteins of imipenem-resistant and -susceptible Acinetobacter baumannii. FEMS Microb Lett 1995; 125: 193-8.

106.- Ampicillin/ sulbactam. Drugdex Drug Evaluation. Micromedex® Healthcare Series 2005; 124.

107.- Valcke Y J, Rosseel M T, Pauwels R A, Bogaert M G, Van der Straeten M E. Penetration of ampicillin and sulbactam in the lower airways during respiratory infections. Antimicrob Agents Chemother 1990; 34: 958-62.

108.- Urban C, Go E, Mariano N, Berger B J, Avraham I, Rubin D, et al. Effect of sulbactam on infections caused by imipenem-resistant Acinetobacter calcoaceticus biotype anitratus. J Infect Dis 1993;
167: 448-51.

109.- Wood G C, Hanes S D, Croce M A, Fabian T C, Boucher B A. Comparison of ampicillin-sulbactam and imipenem-cilastatin for the treatment of Acinetobacter ventilator-associated pneumonia. Clin Infect Dis 2002; 34: 1425-30.

110.- Levin A S, Levy C E, Manrique A E, Medeiros E A, Costa S F. Severe nosocomial infections with imipenem-resistant Acinetobacter baumannii treated with ampicillin/sulbactam. Int J Antimicrob Agents 2003; 21: 58-62.

111.- Jellison T K, McKinnon P S, Rybak M J. Epidemiology, resistance, and outcomes of Acinetobacter baumannii bacteremia treated with imipenemcilastatin or ampicillin-sulbactam. Pharmacotherapy 2001; 21: 142-8.

112.- Horianopoulou M, Kanellopoulou M, Paraskevopoulos I, Kyriakidis A, Legakisand N J, Lambropoulosna $\mathrm{S}$. Use of inhaled ampicillin-sulbactam against multiresistant Acinetobacter baumannii in bronchial secretions of intensive care unit patients. Clin Microbiol Infect 2004; 10: 85-6.

113.- Jiménez Mejías M E, Pachón J, Becerril B, Palomino Nicas J, Rodríguez Cobacho A, Revuelta M. Treatment of multidrug-resistant Acinetobacter baumannii meningitis with ampicillin/sulbactam. Clin Infect Dis 1997; 24: 932-5.

114.- Cawley M J, Suh C, Lee S, Ackerman B H. Nontraditional dosing of ampicillin-sulbactam for multidrug-resistant Acinetobacter baumannii meningitis. Pharmacother 2002; 22: 527-32.

115.- Bello H, Domínguez M, González G, Zemelman R, Mella S, Young $\mathrm{H}$ K et al. In vitro activities of ampicillin, sulbactam and a combination of ampicillin and sulbactam against isolates of Acinetobacter calcoaceticus-Acinetobacter baumannii complex isolated in Chile between 1990 and 1998. J Antimicrob Chemother 2000; 45: 712-3.

116.- Cefoperazone/ sulbactam. Drugdex Drug Evaluation. Micromedex ${ }^{\circledR}$ Healthcare Series 2005. Vol. 124.

117.- Bijie H, Kulpradist S, Manalaysay M, Soebandrio A. In vitro activity, pharmacokinetics, clinical efficacy, safety and pharmacoeconomics of ceftriaxone compared with third and fourth generation cephalosporins: Review. J Chemother 2005; 17: 3-24.

118.- Levin A.S. Multiresistant Acinetobacter infections: a role for sulbactam combinations in overcoming an emerging worldwide problem. Clin Microbiol Infect 2002; 8: 144-153.

119.- Jones R N, Salazar J C, Pfaller M A, Doern G V. Multicenter evaluation of antimicrobial resistance to six broad-spectrum beta-lactams in Colombia using the Etest method. Diagn Microbiol Infect Dis 1997; 29: 265-72.

120.- Miranda M, Olivera M, Barrera L, Martínez E, Villegas M. Clinical response in patients with nosocomial infections caused by multiply-resistant Acinetobacter baumannii treated with cefoperazone/ sulbactam. 42nd Annual Meeting of IDSA, September 30 - October 3, 2004; Boston, USA. Abstract 227.

121.- Acuña C, Rabasseda X. Amoxicillin-sulbactam: A clinical and therapeutic review. Drugs Today 2001 37: 193-210.

122.- Wood G C, Hanes S D, Boucher B A, Croce M A, Fabian T C. Tetracyclines for treating multidrugresistant Acinetobacter baumannii ventilatorassociated pneumonia. Intensive Care Med 2003; 29 : 2072-6. 
123.- Fritsche T R, Strabala P, Sader H S, Jones R N. Activity of tigecycline tested against non-fermentative gram-negative bacilli other than $P$. aeruginosa. 42nd Annual Meeting of IDSA, September 30 October 3, 2004; Boston, USA. Abstract 323.

124.- Martín-Lozano D, Pichardo C, Pachón-Ibáñez M, Jiménez-Mejías M, Rodríguez-Hernández M, Llanos A, et al. Antimicrobial activity of tigecycline (GAR-936) against multiresistant Acinetobacter baumannii. Clin Microbiol Infect 2003; 9 (Suppl 1): 181. P807.

125.- Garnacho Montero J, Ortiz Leyba C, Fernández Hinojosa E. Tratamiento antibiótico de las infeccio- nes graves por Acinetobacter spp. Revista Electrónica de Medicina Intensiva. Junio 2004; 4: C4. http://remi.uninet.edu/2004/06/REMIC04.htm Accedida el 01/09/2004.

126.- Giamarellos-Bourboulis E J, Xirouchaki E, Giamarellou. Interactions of colistin and rifampin on multidrug-resistant Acinetobacter baumannii. Diagn Microbiol Infect Dis 2001; 40: 117-20.

127.- Yoon J, Urban C, Tercian C, et al. In vitro double and triple synergistic activities of polymyxin B, imipenem, and rifampin against multidrug resistant Acinetobacter baumannii. Antimicrob Agents Chemother 2004; 48: 753-7.

Correspondencia a:

Alexis Diomedi Pacheco

adiomedip@entelchile.net

adiomedip@gmail.com 